\title{
Progesterone receptors in normal breast development and breast cancer
}

\author{
Sebastian Giulianelli ${ }^{1,2}$, Caroline A. Lamb ${ }^{1}$ and (1) Claudia Lanari ${ }^{1}$ \\ ${ }^{1}$ Laboratorio de Carcinogénesis Hormonal, Instituto de Biología y Medicina Experimental (IBYME-CONICET), Buenos Aires, Argentina; ${ }^{2}$ LARBIM, Instituto de Biología de Organismos \\ Marinos (IBIOMAR-CCT CONICET-CENPAT), Puerto Madryn, Argentina
}

Correspondence: Claudia Lanari (lanari.claudia@gmail.com)

Received: 21 March 2021

Revised: 04 May 2021

Accepted: 06 May 2021

Version of Record published: 01 June 2021
Progesterone receptors (PR) play a pivotal role in many female reproductive tissues such as the uterus, the ovary, and the mammary gland (MG). Moreover, PR play a key role in breast cancer growth and progression. This has led to the development and study of different progestins and antiprogestins, many of which are currently being tested in clinical trials for cancer treatment. Recent reviews have addressed the role of PR in MG development, carcinogenesis, and breast cancer growth. Thus, in this review, in addition to making an overview on PR action in normal and tumor breast, the focus has been put on highlighting the still unresolved topics on hormone treatment involving PR isoforms and breast cancer prognosis.

\section{Introduction}

Progesterone receptors (PR) are members of the nuclear receptor superfamily (reviewed in [1-8]). The canonical protein structure contains a DNA-binding domain (DBD), a hinge region, and a C-terminal ligand-binding domain (LBD) that includes binding sites for agonists or antagonists [7].

A single copy gene, located on chromosome 11q22, which contains eight exons and seven introns, encodes human PR [9]. PR act as transcription factors activated by their natural ligands or by ligand-independent mechanisms [10].

There are mainly two mRNA transcripts controlled by two different promoters, each one encoding a different protein [11]. The distal promoter of the human gene encodes the full-length PR, named PRB $(116 \mathrm{kDa})$, and the proximal promoter regulates the truncated version, named PRA $(94 \mathrm{kDa})$ which lacks the first 164 amino acids [12-17] (Figure 1A).

Upon ligand activation, dimerized PR translocate to the nucleus, largely in response to a constitutive nuclear localization signal (NLS) located within the hinge region [11]. A mutated NLS leads to cytoplasmic accumulation of PR [18]. A second NLS, located within the DBD, can also mediate ligand-induced nuclear translocation [19]. PRA is preferentially located in the nuclei whereas PRB shuttles from the cytoplasm to the nuclei [20]. Similarly to other steroid receptors, activated PR are visualized as nuclear foci in immunofluorescence assays [21] (reviewed in [22]). Mutations in the DBD usually confer aberrant nuclear compartmentalization of the ligand-bound PR, and larger foci are observed $[23,24]$. It has been hypothesized that PR localized in these nuclear foci or aggregates, corresponds to active PR, and thus, breast carcinomas showing aggregated PR are probably those sensitive to antiprogestin treatment. A recent clinical trial proposes the detection of these activated PR to predict response to treatment with the antiprogestin onapristone (ONA; [25]).

$\mathrm{PR}$ post-translational modifications include phosphorylation, SUMOylation, acetylation, depicted in Figure $1 \mathrm{~B}$, as well as methylation, and ubiquitination (reviewed in [26,27]). These modifications alter PR hormone sensitivity, transcriptional activities, protein down-regulation, nuclear localization, and protein-protein interactions [28]. 


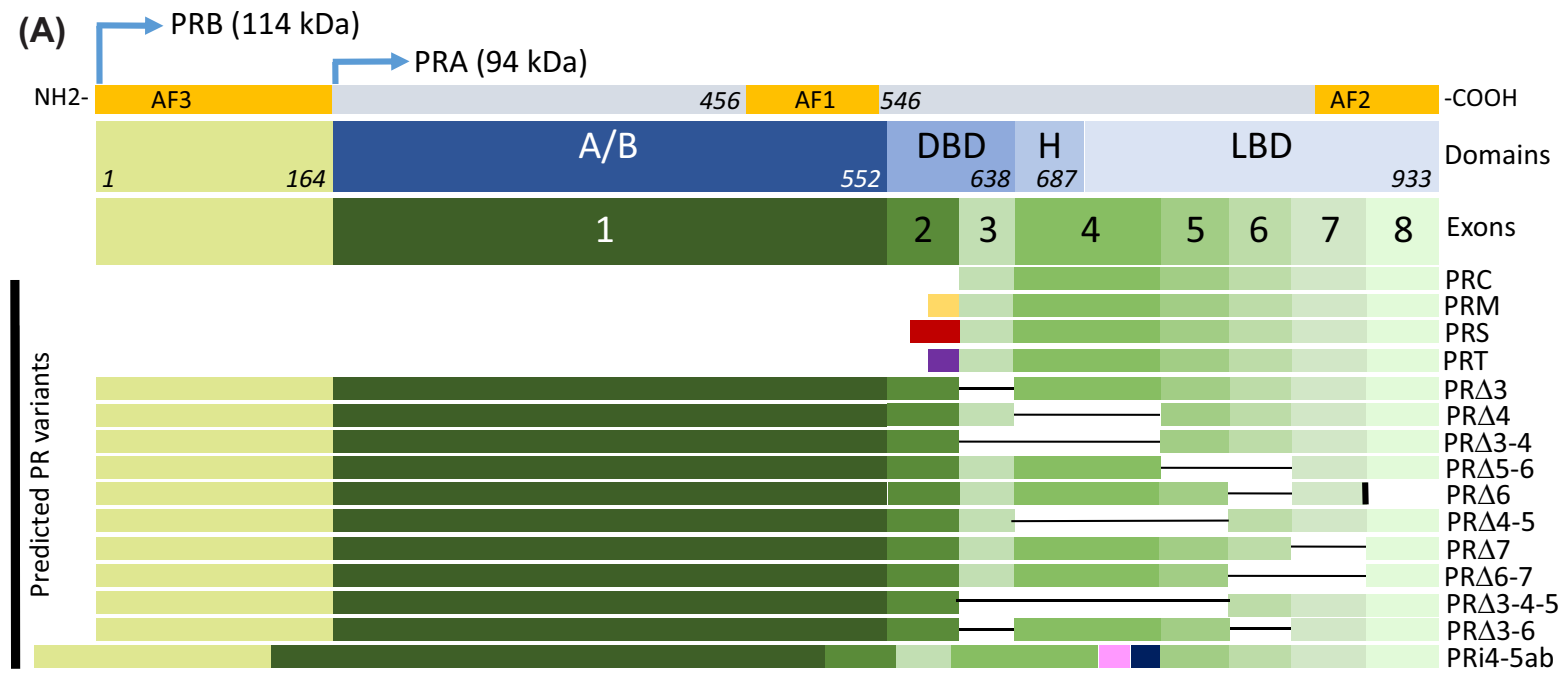

(B)

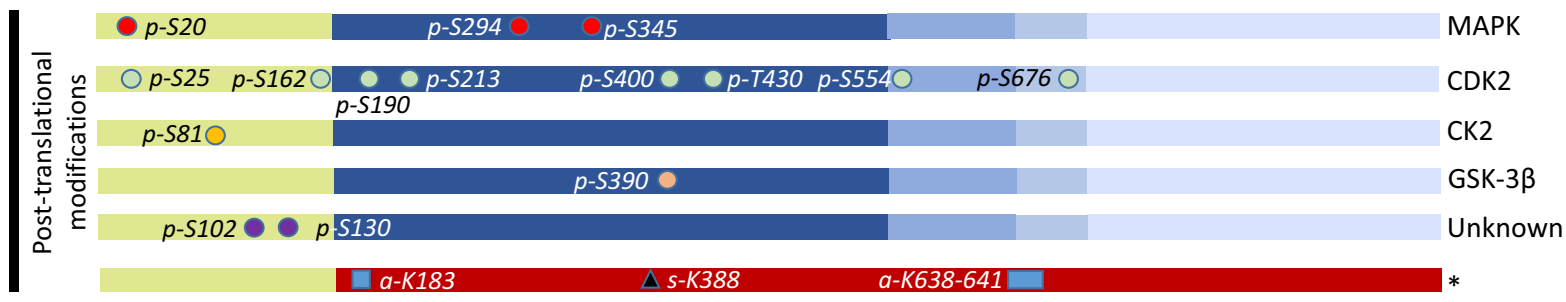

Figure 1. Schematic representation of PR

(A) PR isoforms, activation sites (AF1-3), domains, exons (1-8; modified from Misrahi et al. [10]), predicted variants according to alternative splicing (modified from Hirata et al. [32], Samalecos et al. [30], Cork et al. [31] and Patel et al. [190]), and post-translational modifications (phosphorylations, acetylations and sumoylation; modified from Diep et al. [133]). AF: Activation sites; DBD: DNA-binding domain; H: Hinge; LBD: Ligand-binding domain. Colored rectangles in dark yellow, red, violet, pink or blue account for sequences from introns that are transcribed in selected variants. Black rectangle in PR $\Delta 6$ isoform depicts a truncation site. (B) PR post-translational modifications. Colored circles show phosphorylation ( $p$ ) sites, in red those phosphorylated by MAPK, in light green by CycA/CDK2, in yellow by CK2, in orange by GSK-3 $\beta$, and in violet those phosphorylated by still unidentified kinases. *: Acetylation (a) and sumoylation (s) sites are shown in light blue rectangles and a black triangle, respectively. S: serine residues; T: Threonine residues; K: Lysine residues.

There is a third truncated PR isoform, named PRC $(60 \mathrm{kDa})$, resulting from alternative translation at a methionine at position 595. This form retains the ability to bind the ligand, but not DNA [29]. There are, in addition, several other predicted isoforms from the analysis of alternative splicing mechanisms [30,31]. PRS and PRT retain the intronic sequences before exon 4 and lack the ability to bind DNA suggesting that they may play a role mediating progestin-induced non-genomic effects [32]. PRM mRNA contains a $5^{\prime}$ signal sequence of hydrophobic amino acids, indicating that the protein may be processed for secretion or cell membrane expression [33]. As PRS and PRT, PRM contains the LBD but not the DBD (Figure 1A).

Other mRNA PR variants with different deleted exons (Figure 1A) were detected in breast cancer tissues and cell lines [31,34-38]. Among them, mRNA isoforms with deletions in exons, $7(\Delta 7), 6$ and $7(\Delta 6-7), 4$ and $5(\Delta 4-5)$ and 3,4 and $5(\Delta 3-4-5)$ were found in human breast cancer T47D and MCF-7 cells. $\Delta 7$ and $\Delta 6-7$ were also detected in PR-negative human MDA-MB-231 breast cancer cells [39].

Only PRM, PRC and PRBdelta4 (PRB $\triangle 4)$ were detected as proteins [33,40,41]. Giulianelli et al. demonstrated that PRB $\triangle 4$, which has an impaired LBD and lacks the NLS, was recruited to MYC regulatory sequences following ligand-independent stimulation by FGF2. Moreover, $P R B \triangle 4$ expression was associated with worse overall survival in luminal breast cancer patients [41]. Thus, there is a renewed interest in unraveling the role of these novel PR variants in endocrine resistance (reviewed in [26]). 


\section{PR and mammary gland development}

Many reviews have addressed in detail the different stages of the mammary gland (MG) development [42-44], and many others have focused in the role of progesterone (Pg) and PR in the normal and neoplastic MG [45-53]. Briefly, the MG develops after birth to generate a rudimentary duct tree. During puberty, $17-\beta$-estradiol (E2) and Pg are the main hormones that drive the awakening of the MG. E2 induces duct dilation and elongation and primes the epithelial cells for the Pg-induced cell proliferation and ductal branching. This process will culminate ultimately in the amplification of alveolar progenitor cells to form the lobuloalveolar units [54]. As a result, Pg reshapes gene expression through genomic and epigenomic [55-59] mechanisms (reviewed in [43]).

Only a small fraction of MG cells co-express PR and BrdU [47]. Most of PR+ cells do not proliferate [60-62] suggesting that in response to $\mathrm{Pg}$, luminal cells produce paracrine factors that induce proliferation in neighbor cells [63]. Receptor activator of NFKB (RANKL) [64-69], WNT4 [70], calcitonin [71], amphiregulin [72], CXC chemokine receptor type 4 (CXCR4)/Stromal cell derived factor 1 (CXCL12) [73] , ID4 [74], and ADAMTS18 [75] proved to be key players mediating Pg-induced paracrine cell proliferation (reviewed in [49,76]). Not all PR+ cells produce all of these factors [77], suggesting that specialized PR+ subsets of cells may selectively respond to different stimuli or cell contexts [48]. In addition to the paracrine effect, an autocrine Pg-mediated induction of cell proliferation involves the activation of CCND1 [78].

Using PR knock out (KO) mice [79], specific PRA- and PRB-KO mice [80] and transgenic mice overexpressing PRA or PRB [81] it became evident that PRB is the leading PR isoform involved in MG development [66]. PRA may contribute to alveologenesis since this process still occurs in PRB-KO mice [66] and independently of RANKL and WNT4 (reviewed in [48]). MG from transgenic mice overexpressing PRA showed an increase in branching, ductal hyperplasia, and a disorganized basal cell membrane with loss of cell-cell adhesion [81,82]. Contrarily, PRB-overexpressing mice have reduced branching [83] and an increase in basal stem and luminal progenitor cells [84]. Interestingly, ovariectomy or antiestrogen treatment did not diminish the luminal compartment. Moreover, antiestrogen treatment increased the sphere forming capacity of cells [84]. These studies are aligned with previous reports which demonstrate that (a) Pg increases the number of progenitor cells [85], (b) ovariectomy does not affect the basal compartment [68] and (c) when Pg levels are high, such as in pregnancy [68] or in diestrous [69], there is an increase in cells with a stem cell phenotype.

PRA is highly expressed in the luminal epithelium of virgin mouse MG $[47,86]$, whereas PRB is present in luminal and myoepithelial cells. During pregnancy, the MG achieves its complete development and PRB prevails over PRA. In Pg-treated mice, when Pg was administered for 3-10 days [87], or for one or two months [86], a decrease in total PR was observed favoring the expression of PRB over PRA.

In virgin non-ovariectomized mice, it is the combination of E2 and Pg that generates a fully developed MG. Remarkably, the mouse strain background plays a key role in the degree of hormone responsiveness. While BALB/c mice, a cancer susceptible strain, showed a high response to hormones, the resistant C57BL/6 strain showed lower PR expression levels in virgin mice, and a lower response to pregnancy-related hormones $[86,87]$ than $\mathrm{BALB} / \mathrm{c}$ mice. When MG cells from both strains were transplanted into cleared mammary fat pads from immunosuppressed mice with a different genetic background, the differences between strains disappeared. Comparable PR expression levels were now observed in reconstituted MG, suggesting an important role of the microenvironment regulating PR expression [86]. Thus, in human populations, the intrinsic genetic differences among women may be responsible for multiple basal PR levels and hormone responses, which might also impact in the susceptibility to develop breast cancer.

In the human breast, $\mathrm{PR}$ is co-expressed with ER $\alpha$ with different intensities, as opposed to the homogeneous co-expression of ER $\alpha$ with AR [88]. The meaning of this data is still unknown. Very rarely the normal cells co-express $\mathrm{ER} \alpha, \mathrm{PR}$, and AR [88]. Regarding GR, 77\% of ER $\alpha+/ \mathrm{PR}+$ samples also express GR [89]. Buxant and coworkers also reported that $\mathrm{ER} \alpha, \mathrm{PR}$, and GR are co-expressed in normal breast, however, it is not clear if the same cells express the three receptors [90].

\section{PR and carcinogenesis}

Pg administration has been related to mammary carcinogenesis in rodents (reviewed in [91]). Pg treatment induced mammary carcinomas in intact BALB/c mice [92]. Medroxyprogesterone acetate (MPA), which has glucocorticoid and androgenic, in addition to progestagenic effects [93], was more effective inducing mammary carcinomas than Pg itself [92,94]. The androgenic effects of MPA increasing serum EGF [95] may contribute to increase the MG susceptibility [96]. Conversely, inhibition of PR signaling reduced mammary carcinogenesis [97-100]. 
In women, the impact of progestins administered in oral contraceptives or as hormone replacement therapy has been recently reviewed $[49,51,101]$. There is a consensus that the co-administration of progestins together with estrogens increases breast cancer risk [102,103]. As suggested by Horwitz and Sartorius, progestins may be inducing growth of previously undetectable tumors, rather than having a carcinogenic effect per se [104]. Regimens containing micronized Pg are associated with a significantly lower risk of breast cancer than those containing synthetic progestins [105].

\section{PR in tumor growth Mice}

In the mouse MXT model (ER $\alpha+$ and $\mathrm{PR}+), \mathrm{Pg}$ increased thymidine uptake in tumors growing in ovariectomized mice [106], and these tumors regressed with antiprogestin treatment. The combination with antiestrogens increased their therapeutic efficacy [107].

Hormone receptor positive luminal mammary carcinomas developed in BALB/c mice is the most extensively breast cancer model studied [94,108]. These tumors initially require Pg-or MPA-exogenous administration for their growth [109]. After several passages, tumors may acquire a hormone-independent (HI) pattern of growth. However, they still express ER $\alpha$ and PR and may be responsive to antiprogestin therapies using ONA [110], mifepristone (MFP) [111,112], aglepristone [113], lonaprisan [112] or telapristone acetate (TLP) [113], or to genetic PR expression inhibition [114]. The observation that primary cultures were more successful when stromal cells were present, suggested that the stroma could participate regulating HI growth. Differences in gene expression profiles from HD and HI stromas were confirmed using laser capture micro-dissection and transcriptomics [115]. Activated fibroblasts from HI tumors produced increased FGF2 levels than those from HD tumors [116]. Moreover, in T47D human breast cancer cells, STAT5, FGFR2 and PR interactions were detected at the MYC and CCND1 promoters in MPA- or FGF2-stimulated cells [117]. This may explain why tumors growing in a poor hormonal milieu, as in menopause, may be still using the hormone receptor machinery to support tumor growth. FGF2 also activates ER $\alpha$ in addition to PR, inducing PR expression [41,118]. As mentioned above, FGF2 also activated PR-spliced variants, which were forming part of complexes bound to MYC promoter sequences, suggesting their possible involvement in endocrine resistance.

In terms of relative PR protein levels, tumors of the MPA-induced model which are inhibited by antiprogestins express higher levels of PRA than PRB [112], and are named PRA high (PRA-H). Possibly, the low PRB levels are due to their active role and increased degradation as compared with PRA. Constitutive resistant variants have higher PRB than PRA levels (PRB-H) compared with responsive variants [111]. In these tumors, selective PRA methylation was observed [119]. Treatment with DNA methyltransferases and/or histone deacetylase inhibitors restored PRA expression and antiprogestin responsiveness $[113,119]$. In acquired resistant tumors, which became resistant by continuous pressure with antiprogestin treatment, estrogens or tamoxifen (TAM) restored PRA expression and antiprogestin responsiveness [112]. The clinical implications of these findings are challenging, as they suggest that PRA-H tumors may respond to antiprogestin treatment and, PRB-H tumors may be also treated with antiprogestins combined with TAM or demethylating agents to restore PRA expression.

Increased levels of nuclear and cytosolic FGF2 were observed in tumor cells of acquired-resistant variants [120] suggesting that an increase in an autocrine growth factor signaling loop may hyperactivate PR and induce its degradation [121,122]. In the MG, a subgroup of ER $\alpha$-negative cells as determined by immunohistochemistry (IHC), still express mRNA ESR 1 [123]. A possible explanation is that, in these cells, ER $\alpha$ levels are below the IHC detection limit probably due to a rapid protein turnover [123]. Thus, a new concept is emerging in which cells with very active hormone receptor (HR) might be catalogued as HR negative [48]. If it is this the case that explains the disbalance in $\mathrm{PR}$ isoforms in these tumors, remains to be investigated. Figure 2 illustrates the interaction of the FGF2/FGFR and $\mathrm{PR}$ pathways and their role in tumor progression.

Since PRA-H tumors regress almost completely with antiprogestin treatment, lower antiprogestin doses have been used in combination protocols. The combined treatment with Nab-paclitaxel or pegylated doxorubicin liposomes (Peg-doxo) exerted a higher tumor growth inhibition than the respective monotherapies. MFP increased the tumor microvasculature that allowed a greater entry of nanoparticles [124]. In addition, MFP increased the exposure of DAMPS in tumor cells, which activate the immune system so that combined therapies of MFP and anti-PDL1 antibodies inhibited tumor growth in a higher degree than each treatment alone [125]. Again, this illustrates that targeting $\mathrm{PR}$ in these tumors may be an interesting tool to potentiate the effect of other therapies.

In the Her2/neu transgenic mouse model of breast cancer, although primary tumors are PR-, it has been proposed that Pg, while increasing MG branching, contributes to the early dissemination of tumor cells [126]. 
(A) Progestin-dependent tumor cell

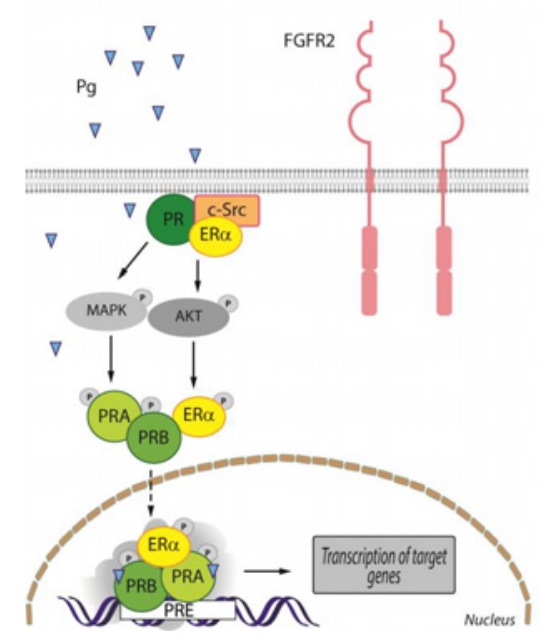

(B) Progestin-independent antiprogestin responsive tumor cell

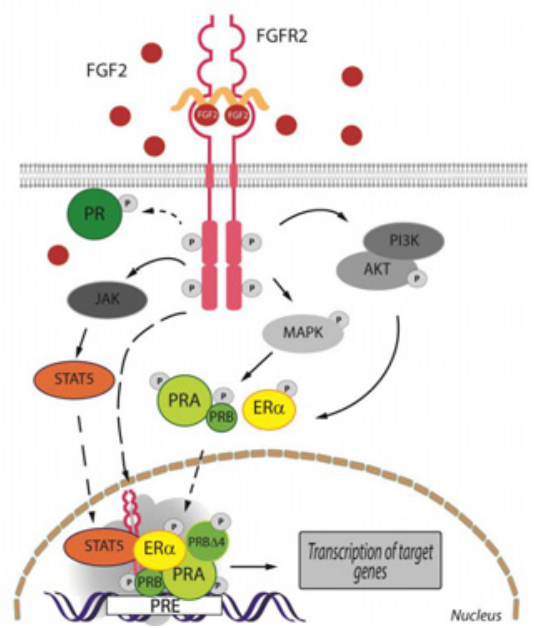

(C) Progestin-independent antiprogestin resistant tumor cell

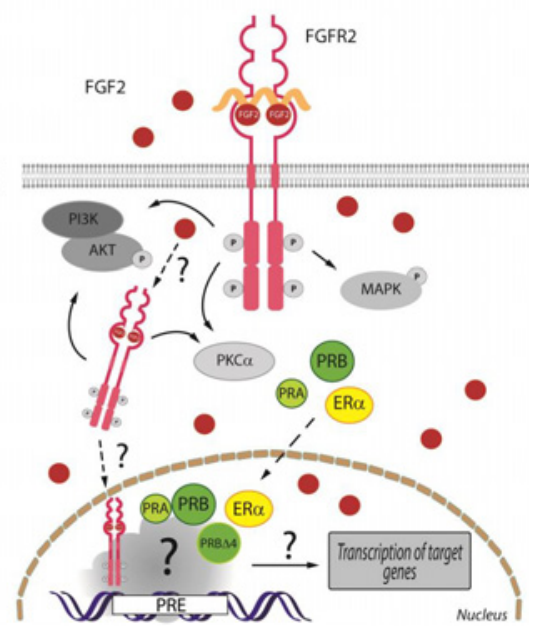

Figure 2. Model illustrating the crosstalk between PR and FGF/FGFR pathways

(A) Progestin-dependent activation of PR. In progestin-dependent tumor cells, progestins bind PR in the membrane/cytosolic compartment inducing rapid activation of MAPK and AKT signaling pathways via ER $\alpha / P R / c-S r c$ complexes. Next, phosphorylated PR isoforms, translocate to the nuclei. Active PRA and PRB bind to progesterone responsive elements (PRE) and recruit coactivators, including $E R \alpha$ that induce gene transcription, which in turn, triggers cell proliferation. (B) Progestin-independent PR activation in antiprogestin responsive (PRA-H) tumor cells. In antiprogestin responsive progestin-independent tumor cells, FGF2 mainly secreted by carcinoma associated fibroblasts, binds FGFR and induces downstream activation of intracellular signaling pathways which, in turn, phosphorylate ER $\alpha$ and PR. PR variants, such as PRBs $\Delta 4$ which are not activated by progestins can also be activated by FGF2. As a result, active PR bind PRE-sites forming transcriptional complexes with coactivators such as ER $\alpha$, STAT5, FGFR2, $\mathrm{PRB} \triangle 4$ that trigger transcription of target genes. (C) Progestin-independent PR activation in antiprogestin resistant (PRB-H) tumor cells. In this scenario, FGF2 is produced mainly by the tumor cells that may bind both membrane and cytosolic FGFRs which activates PKC $\alpha$, MAPK and AKT which, in turn may, phosphorylate ER $\alpha$ and PR. This constitutively phosphorylated state may contribute to a high PR turnover and may explain receptor down-regulation. The role of hormone receptors and the molecular mechanisms by which FGF2-mediates antiprogestin resistance are under investigation. Adapted from Figueroa et al. [191].

\section{Rat}

The chemical carcinogens 7,12-dimethylbenz[a]anthracene (DMBA) or N-Nitroso-N-methylurea (MNU) induce hormone-dependent mammary carcinomas in intact rats (reviewed in [52,91]). Interestingly, in the DMBA-induced model, megestrol acetate (MA), a synthetic progestin, and MFP at similar doses, both exerted inhibitory effects in tumor load. MFP was more potent than MA [127] and was as effective as TAM [128]. MFP-induced inhibitory effect was corroborated by others [129,130]. Similarly, ONA plus TAM had a higher efficacy than MA plus TAM [131]. Using micronized Pg (10 mg/kg/day), an increase in tumor growth was observed whereas MFP or TLP, at the same doses, exerted inhibitory effects. In the MNU-induced model, ONA or MFP inhibited the growth of established tumors [132] which was further improved in combination with TAM [131].

\section{In vivo human experimental models}

The role of PR in in vitro studies using human breast cancer cell lines has been extensively reviewed [26,133,134]. The recent discoveries that $\mathrm{ER} \alpha$ interact with $\mathrm{PR}$ in transcriptional complexes [135,136], and that Pg treatment induces the repositioning of $\mathrm{ER} \alpha$ as a PR cofactor [137], has changed the paradigm of $\mathrm{ER} \alpha$ and PR signaling. Hence, there is a renewed interest in the use of PR ligands to regulate breast cancer growth.

Table 1 describes the experiments performed in human luminal breast cancer cell lines growing as xenografts, which use different antiprogestins or Pg as single or combined treatments. Synthetic progestins have been excluded for clarity, although the results were in line with those using Pg, but with more accentuated effects [138,139]. As a rule, antiprogestins showed inhibitory effects [113,124,140-142] that were potentiated by TAM. Pg showed inhibitory [137], stimulatory [143] or no effects $[138,144,145]$, depending on the protocol used. Tumor regression (negative 


\begin{tabular}{|c|c|c|c|c|c|c|c|c|c|c|}
\hline Model & $\begin{array}{l}\text { Mouse } \\
\text { strain }\end{array}$ & Matrigel & $\begin{array}{l}\text { E2 pellet } \\
\text { (mg) }\end{array}$ & Treatment & Dose & $\begin{array}{l}\text { Tumor } \\
\text { size; Time } \\
\text { (days) at } \\
\text { treatment } \\
\text { initiation }\end{array}$ & Method & $\begin{array}{c}\% \\
\text { increase } \\
(\uparrow) \text { or } \\
\text { decrease } \\
(\downarrow) \text { in final } \\
\text { tumor size } \\
\text { versus } \\
\text { control } \\
\text { (days after } \\
\text { treatment) }\end{array}$ & Slope & Refs. \\
\hline \multirow[t]{4}{*}{ MCF-7 } & Intact Nude & No & $0.72-1.7$ & $\begin{array}{c}\text { TAM } \\
\text { MFP } \\
\text { MFP+TAM } \\
\text { ONA } \\
\text { ONA+TAM }\end{array}$ & $\begin{array}{c}15 \mathrm{mg} \text { pellet } \\
50 \\
\mathrm{mg} / \mathrm{kg} / \text { day, } \\
\mathrm{sc} \\
\text { Combo } \\
30 \\
\mathrm{mg} / \mathrm{kg} / \mathrm{day}, \\
\mathrm{sc} \\
\text { Combo }\end{array}$ & $\begin{array}{c}200-330 \\
\mathrm{~mm}^{3} \\
22-52\end{array}$ & C & $\begin{array}{c}\downarrow 40 \%(17 \mathrm{~d}) \\
\downarrow 55 / 49 \%(37 \\
d) \\
\downarrow 41 \% \text { (17 d) } \\
\downarrow 50 \% \text { (37 d) } \\
\downarrow 62 \% \text { (17 d) } \\
\downarrow 70 \% \text { (37 d) } \\
\downarrow 46 \%(17 \mathrm{~d}) \\
\downarrow 53 \%(17 \mathrm{~d})\end{array}$ & $\begin{array}{l}+ \\
+ \\
+ \\
+ \\
+\end{array}$ & [141] \\
\hline & Intact NSG & Yes & 0.72 & $\mathrm{Pg}$ & $10 \mathrm{mg}$ pellet & $\begin{array}{l}? \\
7\end{array}$ & $B \& C$ & $\begin{array}{c}\approx \downarrow 38 \%(21 \\
\text { d) }\end{array}$ & + & [137] \\
\hline & $\begin{array}{l}\text { OVX } \\
\text { NSG }\end{array}$ & Yes & 0.72 & $\mathrm{Pg}$ & $10 \mathrm{mg}$ pellet & $\begin{array}{l}? \\
7\end{array}$ & $\begin{array}{c}B \& C \\
N V\end{array}$ & $\begin{array}{c}\approx 0 \%(21 d) \\
\approx \downarrow 36 \%(45 \\
\text { d) }\end{array}$ & + & \\
\hline & Intact NSG & Yes & 0.72 & $\begin{array}{c}\text { TAM } \\
\mathrm{Pg} \\
\text { TAM+Pg }\end{array}$ & $\begin{array}{c}0.5 \mathrm{mg} 3 \\
\text { days/1 off, ip } \\
10 \mathrm{mg} \text { pellet } \\
\text { Combo }\end{array}$ & $\begin{array}{l}? \\
7\end{array}$ & $\begin{array}{l}\text { B } \\
\text { NV }\end{array}$ & $\begin{array}{l}\downarrow 59 \%(35 d) \\
\downarrow 75 \%(47 d) \\
\downarrow 50 \%(35 d) \\
\downarrow 53 \%(47 d) \\
\downarrow 78 \%(35 d) \\
\downarrow 90 \%(47 d)\end{array}$ & $\begin{array}{l}+ \\
+ \\
+\end{array}$ & \\
\hline \multirow[t]{2}{*}{ MCF-7 EV } & Intact Nude & No & 0.72 & $\mathrm{Pg}$ & $10 \mathrm{mg}$ pellet & $\begin{array}{c}100 \mathrm{~mm}^{3} \\
12\end{array}$ & C & $\begin{array}{l}\approx 0 \%(16 \mathrm{~d}) \\
\approx 0 \%(33 \mathrm{~d})\end{array}$ & + & [141] \\
\hline & OVX Nude & No & 0.72 & $\mathrm{Pg}$ & $10 \mathrm{mg}$ pellet & $\begin{array}{c}100 \mathrm{~mm}^{3} \\
10\end{array}$ & C & $\begin{array}{l}\approx 0 \%(28 d) \\
\approx 0 \%(40 d)\end{array}$ & + & [140] \\
\hline \multirow[t]{6}{*}{$\begin{array}{l}\text { T47D } \\
\text { P53* }\end{array}$} & OVX Nude & Yes & 2 & $\mathrm{Pg}$ & $10 \mathrm{mg}$ pellet & $\begin{array}{c}100 \mathrm{~mm}^{3} \\
28\end{array}$ & C & $\approx 0 \%(28 \mathrm{~d})$ & + & [134] \\
\hline & Intact Nude & No & 1.7 & $\mathrm{Pg}$ & $10 \mathrm{mg}$ pellet & $\begin{array}{c}15 \mathrm{~mm}^{3} \\
31\end{array}$ & $\mathrm{C}$ & $\begin{array}{c}\approx \uparrow 550 \% \text { (55 } \\
\text { d) }\end{array}$ & + & [135] \\
\hline & Intact NSG & Yes & 0.72 & $\begin{array}{c}\text { TAM } \\
\mathrm{Pg} \\
\mathrm{TAM}+\mathrm{Pg}\end{array}$ & $\begin{array}{c}0.5 \mathrm{mg} 3 \\
\text { days } / 1 \text { off, ip } \\
10 \mathrm{mg} \text { pellet } \\
\text { Combo }\end{array}$ & $\begin{array}{l}? \\
7\end{array}$ & $\begin{array}{c}B \& C \\
N V\end{array}$ & $\begin{array}{c}\approx \downarrow 59 \%(49 \\
\quad d) \\
\approx \downarrow 23 \%(49 \\
\quad d) \\
\approx \downarrow 84 \%(49 \\
\text { d) }\end{array}$ & $\begin{array}{l}+ \\
+ \\
+\end{array}$ & [133] \\
\hline & OVX Nude & Yes & 5 & $\begin{array}{c}\text { TAM } \\
\text { TLP } \\
\text { TAM+TLP }\end{array}$ & $\begin{array}{c}25 \mathrm{mg} \text { pellet } \\
25 \mathrm{mg} \text { pellet } \\
\text { Combo }\end{array}$ & $\begin{array}{c}120 \mathrm{~mm}^{3} \\
?\end{array}$ & $\begin{array}{c}\mathrm{C} \\
\mathrm{NV}\end{array}$ & $\begin{array}{c}\approx \downarrow 88 \%(28 \\
\text { d) } \approx \downarrow 105 \% \\
(49 \mathrm{~d}) \\
\approx \downarrow 140 \%(28 \\
\text { d) } \approx \downarrow 56 \% \\
(49 \mathrm{~d}) \\
\approx \downarrow 150 \%(28 \\
\text { d) } \approx \downarrow 143 \% \\
(49 \mathrm{~d})\end{array}$ & $\begin{array}{l}+/+ \\
-/+ \\
-/-\end{array}$ & [136] \\
\hline & OVX Nude & Yes & 5 & $\begin{array}{c}\text { TAM } \\
\text { CDB4453 } \\
\text { TAM+CDB4453 } \\
\text { EC313 } \\
\text { TAM+EC313 }\end{array}$ & $\begin{array}{c}25 \mathrm{mg} \text { pellet } \\
25 \mathrm{mg} \text { pellets } \\
3 \quad \text { Combo } \\
10 \\
\mathrm{mg} / \mathrm{kg} / \mathrm{day}, \mathrm{ip} \\
\text { Combo }\end{array}$ & $\begin{array}{c}120 \mathrm{~mm}^{3} \\
?\end{array}$ & $\begin{array}{c}\mathrm{C} \\
\mathrm{NV}\end{array}$ & $\begin{array}{c}\approx \downarrow 50 \%(21 \\
\text { d) } \approx \downarrow 85 \% \\
(35 \mathrm{~d}) \\
\approx 0 \%(21 \mathrm{~d}) \\
\approx \downarrow 80 \%(35 \\
\text { d) } \\
\approx \downarrow 100 \%(21 \\
\text { d) } \approx \downarrow 142 \% \\
(35 \mathrm{~d}) \\
\approx \downarrow 50 \%(21 \\
\text { d) } \approx \downarrow \downarrow \downarrow 39 \% \\
(35 \mathrm{~d}) \\
\approx \downarrow 100 \%(21 \\
\text { d) } \approx \downarrow 1135 \% \\
(35 \mathrm{~d})\end{array}$ & $\begin{array}{l}+ \\
+ \\
-/ \\
-/ \\
-/\end{array}$ & [138] \\
\hline & Intact NSG & No & 0.5 & MFP & $\begin{array}{c}10 \\
\mathrm{mg} / \mathrm{kg} / \text { day }\end{array}$ & $\begin{array}{c}30-40 \mathrm{~mm}^{2} \\
10-20\end{array}$ & C & $\begin{array}{c}\approx \downarrow 50 \%(12 \\
\text { d) }\end{array}$ & - & [111] \\
\hline
\end{tabular}




\begin{tabular}{|c|c|c|c|c|c|c|c|c|c|c|}
\hline Model & $\begin{array}{l}\text { Mouse } \\
\text { strain }\end{array}$ & Matrigel & $\begin{array}{c}\text { E2 pellet } \\
\text { (mg) }\end{array}$ & Treatment & Dose & $\begin{array}{l}\text { Tumor } \\
\text { size; Time } \\
\text { (days) at } \\
\text { treatment } \\
\text { initiation }\end{array}$ & Method & $\begin{array}{c}\% \\
\text { increase } \\
(\uparrow) \text { or } \\
\text { decrease } \\
(\downarrow) \text { in final } \\
\text { tumor size } \\
\text { versus } \\
\text { control } \\
\text { (days after } \\
\text { treatment) }\end{array}$ & Slope & Refs. \\
\hline \multirow[t]{2}{*}{$\begin{array}{l}\text { T47D } \\
\text { EV }\end{array}$} & Intact Nude & No & 0.72 & $\mathrm{Pg}$ & $10 \mathrm{mg}$ pellet & $\begin{array}{c}100 \mathrm{~mm}^{3} \\
12\end{array}$ & C & $\begin{array}{l}\approx 0 \%(16 d) \\
\approx 0 \%(33 d)\end{array}$ & + & [141] \\
\hline & OVX Nude & No & 0.72 & $\mathrm{Pg}$ & $10 \mathrm{mg}$ pellet & $\begin{array}{c}100 \mathrm{~mm}^{3} \\
14\end{array}$ & C & $\begin{array}{l}\approx 0 \%(14 d) \\
\approx 0 \%(31 d)\end{array}$ & + & [140] \\
\hline \multirow[t]{2}{*}{ T47D-YA } & OVX Nude & Yes & 2 & $\mathrm{Pg}$ & $10 \mathrm{mg}$ pellet & $\begin{array}{c}100 \mathrm{~mm}^{3} \\
28\end{array}$ & C & $\approx 0 \%(28 \mathrm{~d})$ & + & [134] \\
\hline & Intact NSG & $?$ & 0.5 & $\begin{array}{c}\text { MFP } \\
\text { DoxPEG } \\
\text { MFP+DoxPEG } \\
\text { NabPax } \\
\text { MFP+NabPAX }\end{array}$ & $\begin{array}{c}10 \\
\mathrm{mg} / \mathrm{kg} / \mathrm{day} \\
0.9 \\
\mathrm{mg} / \mathrm{kg} / \text { week } \\
(\times 3) \\
\text { Combo } \\
15 \mathrm{mg} / \mathrm{kg} / 4 \mathrm{~d} \\
(\times 3) \\
\text { Combo }\end{array}$ & $\begin{array}{c}20-30 \mathrm{~mm}^{2} \\
10-20\end{array}$ & C & $\begin{array}{c}\approx \downarrow 45 \%(20 \\
d) \approx \downarrow 50 \% \\
(17 \mathrm{~d}) \\
\approx \downarrow 60 \%(20 \\
\text { d) } \\
\approx \downarrow 85 \%(20 \\
\text { d) } \\
\approx \downarrow 50 \%(20 \\
\text { d) } \\
\approx \downarrow 70 \%(20 \\
\text { d) }\end{array}$ & $\begin{array}{l}0 /- \\
- \\
- \\
- \\
-\end{array}$ & {$[120,111]$} \\
\hline \multirow[t]{2}{*}{ T47D-YB } & OVX Nude & Yes & 2 & $\mathrm{Pg}$ & $10 \mathrm{mg}$ pellet & $\begin{array}{c}100 \mathrm{~mm}^{3} \\
28\end{array}$ & C & $\approx 0 \%(28 \mathrm{~d})$ & & [134] \\
\hline & Intact NSG & $?$ & 0.5 & $\begin{array}{c}\text { MFP } \\
\text { DoxoPEG } \\
\text { MFP+DoxPEG } \\
\text { NabPax } \\
\text { MFP+NabPAX }\end{array}$ & $\begin{array}{c}10 \\
\mathrm{mg} / \mathrm{kg} / \text { day } \\
0.9 \\
\mathrm{mg} / \mathrm{kg} / \text { week } \\
(\times 3) \\
\mathrm{Combo} \\
15 \mathrm{mg} / \mathrm{kg} / 4 \\
\mathrm{~d}(\times 3) \\
\text { Combo }\end{array}$ & $\begin{array}{c}30-40 \mathrm{~mm}^{2} \\
10-20\end{array}$ & C & $\begin{array}{c}\approx 0 \%(20 \mathrm{~d}) \\
\approx \uparrow 13 \%(17 \\
d) \\
\approx \downarrow 30 \%(20 \\
d) \\
\approx \downarrow 30 \%(20 \\
d) \\
\approx \downarrow 100 \%(20 \\
d) \\
\approx \downarrow 65 \%(20 \\
\text { d) }\end{array}$ & $\begin{array}{c}+/+ \\
+ \\
+ \\
- \\
-\end{array}$ & {$[120,111]$} \\
\hline $\begin{array}{l}\text { BT-474 } \\
\text { Her2+ } \\
\text { P53* }^{*}\end{array}$ & Intact Nude & No & 1.7 & $\begin{array}{c}\mathrm{Pg} \\
\mathrm{MFP} \\
\mathrm{Pg}+\mathrm{MFP} \\
\mathrm{Pg}\end{array}$ & $\begin{array}{c}10 \mathrm{mg} \text { pellet } \\
25 \mathrm{mg} \text { pellet } \\
\text { Combo } \\
10 \mathrm{mg} \text { pellet }\end{array}$ & $\begin{array}{c}25-40 \mathrm{~mm}^{3} \\
8-12\end{array}$ & $\mathrm{C}$ & $\begin{array}{c}\approx \uparrow 300(46 \text { d) } \\
\approx \uparrow 350 \%(52 \\
d) \\
\approx \downarrow 40 \%(46 \\
\text { d)- } \\
\approx \downarrow 64 \%(46 \\
\text { d)- } \\
\approx \uparrow 400 \%(52 \\
\text { d) }\end{array}$ & $\begin{array}{l}+ \\
- \\
- \\
+\end{array}$ & [135] \\
\hline $\begin{array}{l}\text { IBH-6 } \\
\text { EV }\end{array}$ & Intact Nude & No & No & MFP & $\begin{array}{c}10 \\
\mathrm{mg} / \mathrm{kg} / \mathrm{day}\end{array}$ & $\begin{array}{c}8-10 \mathrm{~mm}^{2} \\
15-20\end{array}$ & $\mathrm{C}$ & $\begin{array}{c}\approx \uparrow 200 \%(20 \\
\text { d) }\end{array}$ & + & [111] \\
\hline IBH-6-PRA & Intact Nude & No & No & MFP & $\begin{array}{c}10 \\
\mathrm{mg} / \mathrm{kg} / \text { day }\end{array}$ & $\begin{array}{c}8-10 \mathrm{~mm}^{2} \\
15-20\end{array}$ & C & $\begin{array}{c}\approx 50 \%(15 \\
\text { d) }\end{array}$ & + & [111] \\
\hline IBH-6-PRB & Intact Nude & No & No & MFP & $\begin{array}{c}10 \\
\mathrm{mg} / \mathrm{kg} / \text { day }\end{array}$ & $\begin{array}{c}8-10 \mathrm{~mm}^{2} \\
15-20\end{array}$ & C & $\begin{array}{c}\approx \uparrow 140 \%(20 \\
\text { d) }\end{array}$ & + & [111] \\
\hline
\end{tabular}

Abbreviations: B, bioluminescent imaging; C, caliper; CDB4453, PR antagonist; DoxPEG, pegylated doxorubicin; EC313, selective PR modulator; EV, cell line transfected with an empty vector; ip, intraperitoneal administration; MFP, mifepristone; NabPAX, Nab-paclitaxel; NV, normalized volume; ONA, onapristone; OVX, ovariectomized; Pg, progesterone; sc, subcutaneous administration; TAM, tamoxifen; TLP,: telapristone; *mutated.

slopes) was only observed with the combined treatment of antiprogestins and TAM. In models uniquely expressing PRA, TAM [146] and MFP [113,124] inhibited tumor growth whereas those expressing only PRB were TAM- [138] and MFP- [113] resistant. In addition, the latter grew faster than the former [113,146]. These results support the concept that PRA-H tumors respond to endocrine treatments. 

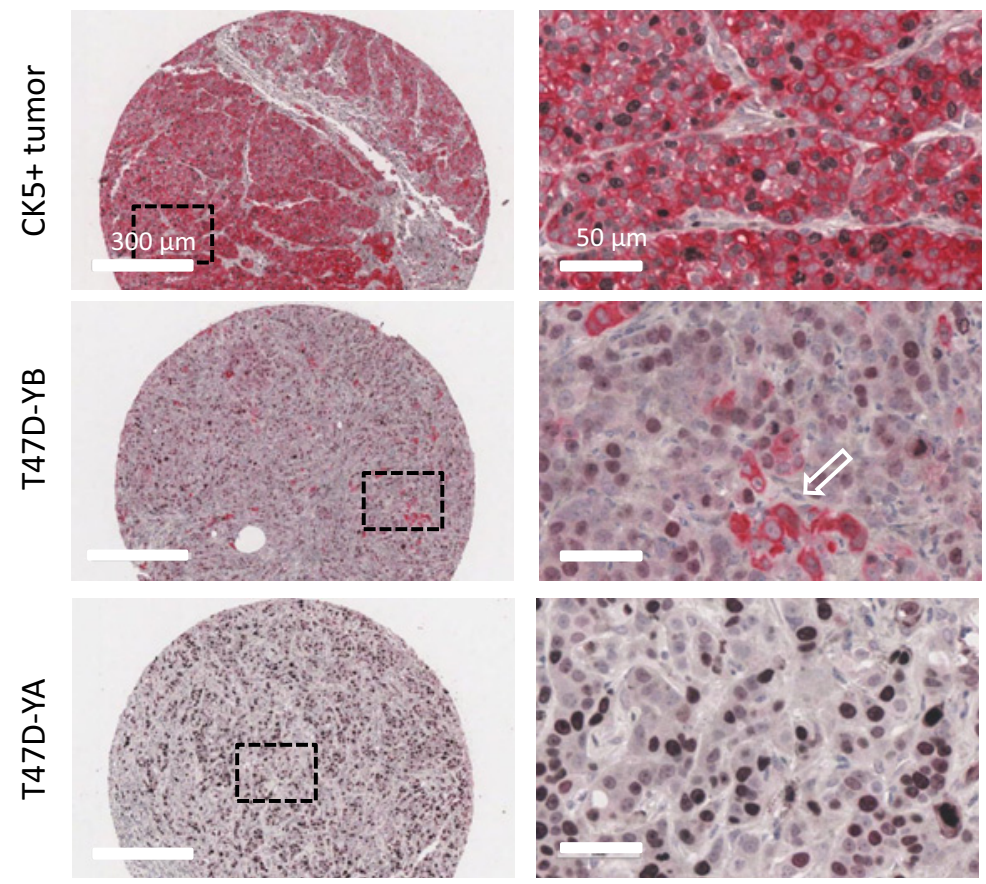

Figure 3. CK5 and Ki-67 expression in breast cancer xenografts of cells expressing only PRA (T47D-YA) or PRB (T47D-YB) CK5 and Ki-67 expression were evaluated using immunohistochemical techniques using a double staining protocol in a tissue microarray as described [192]. A CK5+ PR negative tumor sample is shown as CK5+ control (upper panel). Whereas no CK5 staining was observed in PRA expressing cells, clusters of CK5+ cells were observed in PRB expressing tumors (arrow; pink staining). Brown nuclei represent Ki-67+ cells (CK5 antibody: CME430; Biocare Medical, Concord, CA; Ki-67: ab15580; Abcam; Cambridge, MA).

Progestins increase cancer stem cells (CSC) not only in the MG but also in human breast cancer cell lines [147-151]. Even when Pg did not increase cell proliferation [138], Pg induced an increase in cytokeratins (CK) 5 and 6 expression, while decreasing the expression of luminal CK. The increase in CSC markers was independent of the PR isoform involved [138]. CK5 has been related to a CSC phenotype by regulating the beta-catenin pathway [152]. T47D-YB xenografts express CK5+ clusters, whereas T47D-YA tumors were CK5- (Figure 3). In vitro, both PR isoforms have been implicated in stemness and, depending on the experimental conditions, it was PRB or PRA the prevailing isoform involved $[84,153,154]$. The data shown in Figure 3 and the fact that CK6, another cytokeratin related to stemness, are differentially expressed in PRB-H as compared with PRA-H breast carcinomas [155], are in line with the hypothesis that PRB-expressing cells in the absence of exogenous PR ligands may have more stem-like characteristics in vivo. However, further investigation is necessary to associate PR isoforms and stemness.

\section{PDX}

In the T-61 model, TAM, ONA, and MFP inhibited tumor growth [156,157]. Progestins inhibited the growth of two E2-treated PDX [158]. Using a different PDX, ulipristal acetate, a progesterone receptor modulator, exerted inhibitory effects on tumor growth [159]. The low success rate in developing PDX from luminal A tumors suggests that current models may not be representative of the most common breast type. The mammary intraductal (MIND) model [160], in which cells are injected through the nipple into the mouse milk duct, may provide in the future more information regarding the role of PR ligands in PDX tumor growth.

\section{Breast cancer}

$\mathrm{PR}$ is one of the four markers that defines prognosis and treatment (reviewed in [161]). Breast tumors are classified as luminal (ER $\alpha+$; PR+/-; HER2-), HER2 (ER $\alpha$-; HER2+), or triple negative (TNBC; ER $\alpha$-; PR-; HER2-). Luminal tumors may be subclassified as luminal A (low Ki-67 and high PR) or Luminal B (high Ki-67, PR+/- HER2+/-). In luminal tumors, PR negativity implies worse prognosis either because $\mathrm{ER} \alpha$ are impaired or because tumors have a high growth factor signaling program that induces PR turnover [162]. AR are also frequently expressed in ER $\alpha+$ 
Table 2 List of recently completed or ongoing clinical trials using antiprogestins

\begin{tabular}{|c|c|c|c|c|c|c|c|}
\hline Treatment & Trial identifier & Phase & Drug schedule & Patients & $\begin{array}{c}\text { Patients } \\
\text { characteristics }\end{array}$ & Start date & Status [2021] \\
\hline Onapristone & NCT02052128 & $1 / \|$ & $\begin{array}{l}10,20,30,40,50, \\
\text { and } 100 \mathrm{mg} P O \\
\text { BID for } 57 \text { days }\end{array}$ & $\begin{array}{l}60 \\
\text { Randomized }\end{array}$ & $\begin{array}{c}\text { Postmenopausal, } \\
\text { PR+ BC }\end{array}$ & 2014 & Unknown [193] \\
\hline Onapristone & $\begin{array}{l}\text { NCT04142892 } \\
\text { ONAWA }\end{array}$ & WOO & $\begin{array}{c}50 \text { mg PO BID for } 3 \\
\text { weeks }\end{array}$ & $\begin{array}{c}10 \\
\text { Single group }\end{array}$ & $\begin{array}{c}\text { Postmenopausal } \\
\text { ER+, PR+, } \\
\text { HER2-BC }\end{array}$ & 2020 & Recruiting \\
\hline $\begin{array}{l}\text { Onapristone+ } \\
\text { Fulvestrant }\end{array}$ & $\begin{array}{l}\text { NCT04738292 } \\
\text { SMILE }\end{array}$ & $\|$ & $\begin{array}{l}50 \text { mg PO BID for } \\
\text { up to } 3 \text { years }\end{array}$ & $\begin{array}{l}39 \\
\text { Single group }\end{array}$ & $\begin{array}{l}\text { ER+, HER2-, } \\
\text { Metastatic BC: } \\
\text { after progression } \\
\text { on endocrine and } \\
\text { CDK4/6 therapies }\end{array}$ & 2021 & Not yet recruiting \\
\hline $\begin{array}{l}\text { Telapristone } \\
\text { acetate }\end{array}$ & NCT01800422 & WOO & $\begin{array}{l}12 \text { mg PO QD for } \\
\text { 2-10 weeks }\end{array}$ & $\begin{array}{l}50 \\
\text { Randomized }\end{array}$ & $\begin{array}{c}\text { Stage T1-2, N0-1 } \\
\text { BC }\end{array}$ & 2013 & $\begin{array}{c}\text { Active, not recruiting } \\
{[194]}\end{array}$ \\
\hline $\begin{array}{l}\text { Telapristone } \\
\text { acetate }\end{array}$ & $\begin{array}{c}\text { NCT02314156 } \\
\text { (Prevention) }\end{array}$ & $\|$ & $\begin{array}{c}12 \text { mg breast } \\
\text { transdermal versus } \\
12 \text { mg oral QD for } 4 \\
\text { weeks }\end{array}$ & $\begin{array}{c}67 \\
\text { Randomized }\end{array}$ & $\begin{array}{l}\text { BRCA1 and } \\
\text { BRCA2 carriers } \\
\text { Stages 0-2 BC }\end{array}$ & 2015 & $\begin{array}{c}\text { Active, not recruiting } \\
{[195]}\end{array}$ \\
\hline Mifepristone & $\begin{array}{c}\text { NCT02651844 } \\
\text { MIPRA }\end{array}$ & WOO & $\begin{array}{c}200 \text { mg PO QD for } \\
2 \text { weeks }\end{array}$ & $\begin{array}{c}20 \\
\text { Single arm }\end{array}$ & $\begin{array}{l}\text { Postmenopausal; } \\
\text { PRA/PRB } \geq 1.5 \text {. } \\
\text { Total PR } \geq 50 \% \text { BC }\end{array}$ & 2016 & Completed \\
\hline $\begin{array}{l}\text { Mifepristone*+ } \\
\text { Pembrolizumab }\end{array}$ & NCT03225547 & $\|$ & $\begin{array}{l}300 \text { mg PO QD for } \\
\text { up to } 100 \text { months }\end{array}$ & $\begin{array}{l}74 ; 10 \text { for safety } \\
\text { Non-randomized }\end{array}$ & $\begin{array}{c}\text { Advanced BC. 1: } \\
\text { TNBC; } 2 \text { : ER+ } \\
\text { hormone refractory, } \\
\text { or with } \downarrow \text { ER/PR } \\
\text { expression }\end{array}$ & 2018 & Recruiting \\
\hline $\begin{array}{l}\text { Mifepristone* }+ \\
\text { Abraxane }\end{array}$ & NCT02788981 & $\|$ & $\begin{array}{c}300 \text { mg PO on day } \\
0 \text { and days } 1,7,8, \\
\text { 14, } 15 \text { of each } \\
\text { Abraxane (28-day } \\
\text { cycle). Up to } 12 \\
\text { months }\end{array}$ & $\begin{array}{c}64 \\
\text { Randomized }\end{array}$ & $\begin{array}{c}\text { Advanced GR+ BC, } \\
\text { TNBC }\end{array}$ & 2017 & Recruiting \\
\hline $\begin{array}{l}\text { Mifepristone* }+ \\
\text { Abraxane }\end{array}$ & NCT01493310 & 1 & $\begin{array}{c}300,600,900, \\
1200 \text { mg PO on } \\
\text { days } 0,1,7,8,14, \\
\text { and } 15 \text { combined } \\
\text { with Abraxane. Up } \\
\text { to } 28 \text { days ( } 1 \text { cycle) }\end{array}$ & $\begin{array}{c}9 \\
\text { Randomized }\end{array}$ & Advanced BC & 2011 & Completed \\
\hline $\begin{array}{l}\text { Mifepristone*+ } \\
\text { Gemcitabine+ } \\
\text { carboplatin }\end{array}$ & NCT02046421 & $\begin{array}{c}\text { I } \\
\mathrm{DE}\end{array}$ & $\begin{array}{c}\text { PO, QD on days } 0, \\
1,7,8 \text {, up to } 12 \\
\text { weeks ( } 21 \text {-day } \\
\text { cycle) }\end{array}$ & $\begin{array}{c}31 \\
\text { Single Group }\end{array}$ & $\begin{array}{c}\text { Advanced BC, } \\
\text { HER2- }\end{array}$ & 2013 & Completed \\
\hline $\begin{array}{l}\text { Mifepristone*+ } \\
\text { Eribulin }\end{array}$ & NCT02014337 & $\begin{array}{l}\mathrm{I} / \mathrm{II} \\
\mathrm{DE}\end{array}$ & $\begin{array}{c}\text { PO QD for } 21-28 \\
\text { days (21-day cycle) }\end{array}$ & $\begin{array}{l}\text { Part 1/2: } 20 \text { each } \\
\quad \text { Single arm }\end{array}$ & $\begin{array}{c}\text { Part 1: Advanced } \\
\text { BC } \\
\text { Part2: Advanced } \\
\text { GR+ TNBC }\end{array}$ & 2014 & Completed \\
\hline Mifepristone & $\begin{array}{c}\text { NCT01898312 } \\
\text { (Prevention) }\end{array}$ & $\begin{array}{l}\| \\
P\end{array}$ & $\begin{array}{c}50 \text { mg PO every } \\
\text { second day for } 12 \\
\text { weeks }\end{array}$ & $\begin{array}{l}45 \\
\text { Randomized }\end{array}$ & $\begin{array}{l}\text { Premenopausal } \\
\text { breast tissue; } \\
\text { BRCA 1/2 carriers }\end{array}$ & 2013 & Recruiting \\
\hline $\begin{array}{l}\text { Ulipristal } \\
\text { Acetate }\end{array}$ & $\begin{array}{c}\text { NCT02408770 } \\
\text { BC-APPS1 }\end{array}$ & $\begin{array}{l}\| \\
P\end{array}$ & $\begin{array}{c}5 \mathrm{mg} \text { QD for } 3 \\
\text { months }\end{array}$ & $\begin{array}{c}30 \\
\text { Single group }\end{array}$ & $\begin{array}{c}\text { Premenopausal } \\
\text { BRCA1/2 carriers } \\
\text { or increased BC } \\
\text { risk }\end{array}$ & 2016 & Active, not recruiting \\
\hline $\begin{array}{l}\text { Ulipristal } \\
\text { Acetate }\end{array}$ & NCT02922127 & $\begin{array}{l}1 \\
P\end{array}$ & $\begin{array}{c}10 \text { mg PO QD up } \\
\text { to } 3 \text { months versus } \\
\text { COC pill (28-day } \\
\text { cycle) }\end{array}$ & $\begin{array}{l}29 \\
\text { Randomized }\end{array}$ & $\begin{array}{c}\text { Healthy } \\
\text { premenopausal } \\
\text { women }\end{array}$ & 2016 & Completed \\
\hline
\end{tabular}

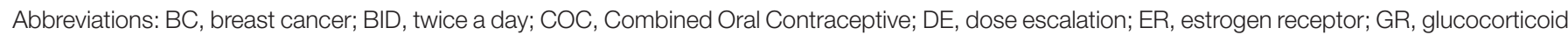

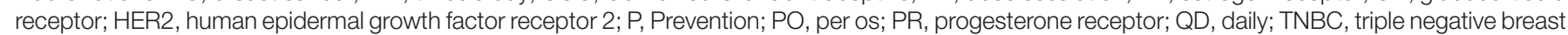
cancer; WOO, Window of opportunity trial; *used as an anti-glucocorticoid; : only antiprogestin dose administration is specified in this table. 
Table 3 List of recently completed or ongoing clinical trials using progestins

\begin{tabular}{|c|c|c|c|c|c|c|c|}
\hline Treatment & Trial identifier & Phase & Drug schedule & Patients & $\begin{array}{c}\text { Patients } \\
\text { characteristics }\end{array}$ & Start date & Status [2021] \\
\hline Pg+Tamoxifen & $\begin{array}{c}\text { ISRCTN23662758 } \\
\text { PEARL }\end{array}$ & WOO & $\begin{array}{c}300 \text { mg micronized } \\
\text { Pg PO QD + } \\
\text { Tamoxifen for } \\
14-18 \text { days }\end{array}$ & $\begin{array}{c}112 \\
\text { Randomized }\end{array}$ & $\begin{array}{c}\text { Premenopausal } \\
\text { ER+, PR+, HER2- } \\
\text { early BC }\end{array}$ & 2019 & Completed \\
\hline $\begin{array}{l}\text { Pg+Letrozole/ } \\
\text { Tamoxifen }\end{array}$ & $\begin{array}{c}\text { NCT03906669 } \\
\text { WinPro }\end{array}$ & WOO & $\begin{array}{c}300 \text { mg micronized } \\
\text { Pg PO QD + } \\
\text { Letrozole or } \\
\text { Tamoxifen for } 14 \\
\text { days }\end{array}$ & $\begin{array}{l}200 \\
\text { Randomized }\end{array}$ & $\begin{array}{l}\text { Postmenopausal } \\
\text { ER+, PR, HER2- } \\
\text { early BC }\end{array}$ & 2018 & Recruiting \\
\hline Pg+Vitamin D3 & $\begin{array}{l}\text { NCT01608451 } \\
\text { Neoadjuvancy }\end{array}$ & III & $\begin{array}{c}500 \text { mg IM before } \\
\text { chemotherapy } \\
\text { cycles [4] and } \\
\text { before surgery +/- } \\
\text { Vitamin D3. } \\
\text { Follow-up: } 5 \text { years }\end{array}$ & $\begin{array}{l}800 \\
\text { Randomized }\end{array}$ & $\begin{array}{l}\text { Large operable and } \\
\text { locally advanced } \\
\text { non-metastatic BC }\end{array}$ & 2007 & Active, not recruiting \\
\hline Pg+ Estrogens & $\begin{array}{l}\text { NCT00079248 } \\
\text { Supportive Care }\end{array}$ & NA & $\begin{array}{l}\text { Oral or transdermal } \\
\text { Estrogen }+/- \text { Pg for } \\
\text { at least } 2 \text { years }\end{array}$ & $\begin{array}{l}\text { 2,800-3,000 } \\
\text { Randomized }\end{array}$ & $\begin{array}{l}\text { Previous Stage I or } \\
\text { II BC (no } \\
\text { recurrence) }\end{array}$ & 2002 & Unknown \\
\hline $\begin{array}{l}\text { Hydroxy-Pg } \\
\text { depot }\end{array}$ & NCT00123669 & $\|/\| I$ & $\begin{array}{c}500 \mathrm{mg}, \mathrm{IM} \text {, once } \\
5-14 \text { days prior to } \\
\text { surgery. Follow-up } \\
5 \text { years }\end{array}$ & $\begin{array}{l}1000 \\
\text { Randomized }\end{array}$ & $\begin{array}{l}\text { Unilateral operable } \\
\text { palpable BC }\end{array}$ & 1997 & Completed \\
\hline $\begin{array}{l}\text { Megestrol } \\
\text { acetate+ } \\
\text { Letrozole }\end{array}$ & $\begin{array}{l}\text { NCT03306472 } \\
\text { PIONEER }\end{array}$ & wOO & $\begin{array}{c}40 \text { or } 160 \text { mg QD } \\
\text { for } 15 \text { days }+ \\
\text { Letrozole }\end{array}$ & $\begin{array}{c}189 \\
\text { Randomized }\end{array}$ & $\begin{array}{c}\text { Postmenopausal } \\
\text { Untreated ER+, } \\
\text { HER2- BC }\end{array}$ & 2017 & Recruiting \\
\hline $\begin{array}{l}\text { Megestrol } \\
\text { acetate }\end{array}$ & $\begin{array}{c}\text { NCT03024580 } \\
\text { MEGA }\end{array}$ & $\|$ & $\begin{array}{l}160 \text { mg PO QD } \\
\text { until disease } \\
\text { progression or } \\
\text { unacceptable } \\
\text { toxicity. Compared } \\
\text { with treatment with } \\
\text { aromatase } \\
\text { inhibitors, } \\
\text { Tamoxifen and } \\
\text { Fulvestrant }\end{array}$ & $\begin{array}{c}20 \\
\text { Non-Randomized }\end{array}$ & $\begin{array}{l}\text { Advanced } \mathrm{ER}+\mathrm{BC} \\
\text { Metastatic site } \\
\text { amenable to biopsy }\end{array}$ & 2017 & Recruiting \\
\hline $\begin{array}{l}\text { Megestrol } \\
\text { acetate+ } \\
\text { Everolimus }\end{array}$ & NCT02269670 & $\|$ & $\begin{array}{c}\text { PO QID + } \\
\text { Everolimus for up to } \\
2 \text { years }\end{array}$ & $\begin{array}{l}\text { Non-specified [3] } \\
\text { Single group }\end{array}$ & $\begin{array}{l}\text { ER+, PR+/-, } \\
\text { HER2-, metastatic } \\
\text { or recurrent BC } \\
\text { after exemestane + } \\
\text { everolimus }\end{array}$ & 2014 & Active, not recruiting \\
\hline $\begin{array}{l}\text { MPA +/- CF and } \\
\text { methotrexate }\end{array}$ & NCT00577122 & $\|$ & $\begin{array}{c}1000 \text { mg PO QD } \\
\text { +/- CF and } \\
\text { methotrexate }\end{array}$ & $\begin{array}{c}30 \\
\text { Non-Randomized }\end{array}$ & $\begin{array}{c}\text { Postmenopausal } \\
\text { ER-, PR-Advanced } \\
\text { BC }\end{array}$ & 2007 & $\begin{array}{c}\text { Completed No clinical } \\
\text { benefit }\end{array}$ \\
\hline
\end{tabular}

Abbreviations: BC, breast cancer; BID, twice a day; CF, cyclophosphamide; ER, estrogen receptor; HER2, human epidermal growth factor receptor 2; IM, intramuscular; MPA, medroxyprogesterone acetate; Pg, progesterone; PO, per OS; PR, progesterone receptor; QD, daily; QID, 4 times a day; WOO, Window of opportunity trial; : only progestin dose administration is specified in this table; NA: not applicable

tumors [163,164], mainly in those PR- [165], in a subgroup of TNBC and in most HER2+ tumors (reviewed in [166]). Nuclear co-localization of ER $\alpha$ and PR has been observed in breast cancer samples [135] and co-expression of ER $\alpha$, $\mathrm{PR}$, and AR in the same cells is a frequent event [88]. Only nuclear PR is considered positive. However, cytoplasmic and/or membrane PR localization has been documented in breast cancer samples [88] and in primary cultures of murine carcinoma cells, after short FGF2 stimulation [167].

PR isoforms cannot be accurately discriminated by IHC [168] and a standardized method to quantify isoforms in routine practice is overdue. PRA is the prevailing PR isoform in breast cancer [25,155,169-172]. It has been hypothesized that higher PRA levels than PRB may be observed because of an increased PRB turnover; however, this remains to be confirmed. Regarding tumor prognosis, PRA-H tumors were associated with TAM-resistance [171] but not to therapy with aromatase inhibitors [173]. In contrast, Rojas et al. concluded that PRA-H patients were associated with better prognosis along with lower Ki-67 expression, HER2 + cases and, histological grade than PRB-H samples, and that their transcriptomic profile matched with luminal A tumors [155]. On the other hand, Singhal et al. [142] and Rosati et al. [174] support the concept that PRA-H cells are more metastatic than PRB-H cells. 
A confounding factor is the fact that luminal A tumors have a better prognosis than luminal B tumors. Most of the genes of the PAM50 platform are related to cell proliferation. Thus, considering that PRB-H xenografts grow faster than the PRA-H tumors [113,146], it seems reasonable that PRB-H tumors match with the luminal B subtype [155]. Both PRA-H and PRB-H tumor types contain cancer cells that are able to invade and metastasize sooner or later. Which capacity would be of worse prognosis? A tumor that metastasizes earlier but grows very slowly or a tumor that metastasizes later but grows very fast. Experiments should be designed using metastatic models to evaluate the metastatic versus the proliferative ability of tumors with different PRA/PRB ratios.

\section{Therapies targeting PR: past and present}

Progestins, mainly MA [175,176] and MPA [177,178] and antiprogestins such as MFP [179-181], ONA [182], and lonaprisan [183] have been tested in the past. In all cases, except for lonaprisan, some benefit was observed in most clinical trials. MFP was the first antiprogestin developed and was used to induce abortion. Since at high doses it also exerts anti-glucocorticoid and anti-androgenic effects, it was later approved to treat Cushing disease (reviewed in [184]). Moreover, in patients with leiomyomas, MFP was used to treat patients prior to hysterectomy and a reduced proliferation was observed in the MG [185]. ONA is a pure antiprogestin. Initially, the clinical trial using ONA was terminated earlier due to hepatotoxicity (reviewed in [186]). However, given that the side effects were similar to other antineoplastic agents, this decision has been reconsidered by the Food and Drug Administration, and ONA is currently being tested for breast cancer treatment. This highlights the importance of developing new antiprogestins with high specificity and lower toxicity than those currently available. The fact that progestins have been shown to increase breast cancer risk [187,188], and that antiprogestins, such as MFP, were shown to act as PR agonists in PRB contexts [189] may be some of the reasons to explain the hampered interest in PR ligands. Nowadays, the attention has been focused on exploring new targets that might be used together with standard endocrine therapy. Currently, endocrine treatment in combination with $\mathrm{PI} 3 \mathrm{~K} / \mathrm{mTor}$ and CDK4/CDK6 inhibitors show an increase in disease-free survival. However, these agents have strong side effects that prevent them from using for long periods of time (reviewed in [161]) .

PR ligands are now again in the pipeline of many companies. Ongoing or recently completed clinical trials that are using PR ligands alone or combined with other treatments are shown in Tables 2 and 3.

Analyzing the experimental models examined above, it is mandatory to design strategies to determine which patients will respond better to a PR agonist or a PR antagonist and to investigate whether the same patients would respond to all PR ligands, or conversely, if those inhibited by progestins would be stimulated by antiprogestins or vice versa. The only study that discriminates patients by the PRA/PRB ratio is the MIPRA study.

\section{Summary}

- $\quad$ PR are key receptors mediating MG development and breast cancer.

- PR may be exploited therapeutically.

- PR antagonists in combination with TAM proved to have the best therapeutic performance in several experimental models.

- The PR isoform ratio dictates different behaviors regarding proliferation, stemness, and prognosis.

- The role of PR isoforms in metastasis deserves further investigation as well as the participation of novel spliced variants in endocrine resistant breast cancer.

\section{Competing Interests}

The authors declare that there are no competing interests associated with the manuscript.

\section{Funding}

This work was funded by ANPCYT [PICTO-Gran Logia 2017-118] (to C.A.L.); PICT 2017-1750 (to S.G.); PICT $2017-2073$ (to C.L.)]. 


\section{Author Contribution}

All authors have equally contributed to the planning, execution, and figure design of this study.

\section{Acknowledgements}

We wish to thank Alfredo Molinolo, Moores Cancer Center, UCSD, San Diego for his help in the IHC assay shown in Figure 3 and Kate Horwitz, University of Colorado, for sharing the T47D-YA and-YB cells. We are also grateful to Fundación Sales, Fundación Gador, Fundación IBYME, Fundación Williams and Fundación Barón for their continuous support.

\section{Abbreviations}

AF, activation sites; AR, androgen receptor; CCND1, cyclin D1; CF, cyclophosphamide; CK, cytokeratins; CSC, cancer stem cells; DAMPS, damage-associated molecular patterns; DBD, DNA-binding domain; DMBA, 7,12-dimethylbenz[a]anthracene; E2, 17- $\beta$-estradiol; EGF, epidermal growth factor; $E R \alpha$, estrogen receptor alpha; FGF2, fibroblast growth factor 2; GR, glucocorticoid receptor; H, Hinge; HD, hormone-dependent; HER2, human epidermal growth factor receptor 2; HI, hormone-independent; HR, hormone receptor; IHC, immunohistochemistry; LBD, ligand-binding domain; MA, megestrol acetate; MIND, mammary intraductal; MFP, mifepristone; MG, mammary gland; MNU, N-Nitroso-N-methylurea; MPA, medroxyprogesterone; NLS, nuclear localization signal; ONA, onapristone; PDX, patient derived xenografts; Pg, progesterone; PR, progesterone receptor; PRA, progesterone receptor isoform A; PRB, progesterone receptor isoform B; PRE, progesterone responsive elements; RANKL, receptor activator of NFKB; TAM, tamoxifen; TLP, telapristone acetate.

\section{References}

1 Beato, M., Chalepakis, G., Schauer, M. and Slater, E.P. (1989) DNA regulatory elements for steroid hormones. J. Steroid Biochem. 32, 737-747, https://doi.org/10.1016/0022-4731(89)90521-9

2 Evans, R.M. (1988) The steroid and thyroid hormone receptor superfamily. Science 240, 889-895, https://doi.org/10.1126/science.3283939

3 Giangrande, P.H. and McDonnell, D.P. (1999) The A and B isoforms of the human progesterone receptor: two functionally different transcription factors encoded by a single gene. Recent Prog. Horm. Res. 54, 291-313

4 Green, S. and Chambon, P. (1988) Nuclear receptors enhance our understanding of transcription regulation. Trends Genet. 4, 309-314, https://doi.org/10.1016/0168-9525(88)90108-4

5 Leonhardt, S.A. and Edwards, D.P. (2002) Mechanism of action of progesterone antagonists. Exp. Biol. Med. (Maywood) 227, 969-980, https://doi.org/10.1177/153537020222701104

6 Mangelsdorf, D.J., Thummel, C., Beato, M., Herrlich, P., Schutz, G., Umesono, K. et al. (1995) The nuclear receptor superfamily: the second decade. Cell 83, 835-839, https://doi.org/10.1016/0092-8674(95)90199-X

7 McEwan, I.J. (2016) The nuclear receptor superfamily at thirty. Methods Mol. Biol. 1443, 3-9, https://doi.org/10.1007/978-1-4939-3724-0'1

8 Tsai, M.J. and O'Malley, B.W. (1994) Molecular mechanisms of action of steroid/thyroid receptor superfamily members. Annu. Rev. Biochem. 63, 451-486, https://doi.org/10.1146/annurev.bi.63.070194.002315

9 Rousseau-Merck, M.F., Misrahi, M., Loosfelt, H., Milgrom, E. and Berger, R. (1987) Localization of the human progesterone receptor gene to chromosome 11q22-q23. Hum. Genet. 77, 280-282, https://doi.org/10.1007/BF00284486

10 Misrahi, M., Venencie, P.Y., Saugier-Veber, P., Sar, S., Dessen, P. and Milgrom, E. (1993) Structure of the human progesterone receptor gene. Biochim. Biophys. Acta 1216, 289-292, https://doi.org/10.1016/0167-4781(93)90156-8

11 Kastner, P., Krust, A., Turcotte, B., Stropp, U., Tora, L., Gronemeyer, H. et al. (1990) Two distinct estrogen-regulated promoters generate transcripts encoding the two functionally different human progesterone receptor forms A and B. EMBO J. 9, 1603-1614, https://doi.org/10.1002/j.1460-2075.1990.tb08280.x

12 Conneely, O.M., Maxwell, B.L., Toft, D.O., Schrader, W.T. and O'Malley, B.W. (1987) The A and B forms of the chicken progesterone receptor arise by alternate initiation of translation of a unique mRNA. Biochem. Biophys. Res. Commun. 149, 493-501, https://doi.org/10.1016/0006-291X(87)90395-0

13 Gronemeyer, H., Turcotte, B., Quirin-Stricker, C., Bocquel, M.T., Meyer, M.E., Krozowski, Z. et al. (1987) The chicken progesterone receptor: sequence, expression and functional analysis. EMBO J. 6, 3985-3994, https://doi.org/10.1002/j.1460-2075.1987.tb02741.x

14 Horwitz, K.B. and Alexander, P.S. (1983) In situ photolinked nuclear progesterone receptors of human breast cancer cells: subunit molecular weights after transformation and translocation. Endocrinology 113, 2195-2201, https://doi.org/10.1210/endo-113-6-2195

15 Kastner, P., Bocquel, M.T., Turcotte, B., Garnier, J.M., Horwitz, K.B., Chambon, P. et al. (1990) Transient expression of human and chicken progesterone receptors does not support alternative translational initiation from a single mRNA as the mechanism generating two receptor isoforms. J. Biol. Chem. 265, 12163-12167, https://doi.org/10.1016/S0021-9258(19)38326-7

16 Krett, N.L., Wei, L.L., Francis, M.D., Nordeen, S.K., Gordon, D.F., Wood, W.M. et al. (1988) Human progesterone A-receptors can be synthesized intracellularly and are biologically functional. Biochem. Biophys. Res. Commun. 157, 278-285, https://doi.org/10.1016/S0006-291X(88)80044-5

17 Schrader, W.T. and O'Malley, B.W. (1972) Progesterone-binding components of chick oviduct. IV. Characterization of purified subunits. J. Biol. Chem. 247, 51-59, https://doi.org/10.1016/S0021-9258(19)45757-8

18 Kakar, M., Kanwal, C., Davis, J.R., Li, H. and Lim, C.S. (2006) Geldanamycin, an inhibitor of Hsp90, blocks cytoplasmic retention of progesterone receptors and glucocorticoid receptors via their respective ligand binding domains. AAPS J. 8, E718-E728, https://doi.org/10.1208/aapsj080481 
19 Guiochon-Mantel, A., Loosfelt, H., Lescop, P., Christin-Maitre, S., Perrot-Applanat, M. and Milgrom, E. (1992) Mechanisms of nuclear localization of the progesterone receptor. J. Steroid Biochem. Mol. Biol. 41, 209-215, https://doi.org/10.1016/0960-0760(92)90346-K

20 Lim, C.S., Baumann, C.T., Htun, H., Xian, W., Irie, M., Smith, C.L. et al. (1999) Differential localization and activity of the A- and B-forms of the human progesterone receptor using green fluorescent protein chimeras. Mol. Endocrinol. 13, 366-375, https://doi.org/10.1210/mend.13.3.0247

21 Arnett-Mansfield, R.L., deFazio, A., Mote, P.A. and Clarke, C.L. (2004) Subnuclear distribution of progesterone receptors A and B in normal and malignant endometrium. J. Clin. Endocrinol. Metab. 89, 1429-1442, https://doi.org/10.1210/jc.2003-031111

22 Stortz, M., Presman, D.M., Pecci, A. and Levi, V. (2021) Phasing the intranuclear organization of steroid hormone receptors. Biochem. J. 478, 443-461, https://doi.org/10.1042/BCJ20200883

23 Arnett-Mansfield, R.L., Graham, J.D., Hanson, A.R., Mote, P.A., Gompel, A., Scurr, L.L. et al. (2007) Focal subnuclear distribution of progesterone receptor is ligand dependent and associated with transcriptional activity. Mol. Endocrinol. 21, 14-29, https://doi.org/10.1210/me.2006-0041

24 Graham, J.D., Hanson, A.R., Croft, A.J., Fox, A.H. and Clarke, C.L. (2009) Nuclear matrix binding is critical for progesterone receptor movement into nuclear foci. FASEB J. 23, 546-556, https://doi.org/10.1096/fj.08-113639

25 Bonneterre, J., Bosq, J., Jamme, P., Valent, A., Gilles, E.M., Zukiwski, A.A. et al. (2016) Tumour and cellular distribution of activated forms of PR in breast cancers: a novel immunohistochemical analysis of a large clinical cohort. ESMO Open 1, e000072, https://doi.org/10.1136/esmoopen-2016-000072

26 Dwyer, A.R., Truong, T.H., Ostrander, J.H. and Lange, C.A. (2020) 90 YEARS OF PROGESTERONE: Steroid receptors as MAPK signaling sensors in breast cancer: let the fates decide. J. Mol. Endocrinol. 65, T35-T48, https://doi.org/10.1530/JME-19-0274

27 Leehy, K.A., Regan Anderson, T.M., Daniel, A.R., Lange, C.A. and Ostrander, J.H. (2016) Modifications to glucocorticoid and progesterone receptors alter cell fate in breast cancer. J. Mol. Endocrinol. 56, R99-R114, https://doi.org/10.1530/JME-15-0322

28 Abdel-Hafiz, H.A., Dudevoir, M.L., Perez, D., Abdel-Hafiz, M. and Horwitz, K.B. (2018) SUMOylation Regulates Transcription by the Progesterone Receptor A Isoform in a Target Gene Selective Manner. Diseases 6, 1-16, https://doi.org/10.3390/diseases6010005

29 Wei, L.L., Gonzalez-Aller, C., Wood, W.M., Miller, L.A. and Horwitz, K.B. (1990) $5^{\prime}$-Heterogeneity in human progesterone receptor transcripts predicts a new amino-terminal truncated "C"-receptor and unique A-receptor messages. Mol. Endocrinol. 4, 1833-1840, https://doi.org/10.1210/mend-4-12-1833

30 Samalecos, A. and Gellersen, B. (2008) Systematic expression analysis and antibody screening do not support the existence of naturally occurring progesterone receptor (PR)-C, PR-M, or other truncated PR isoforms. Endocrinology 149, 5872-5887, https://doi.org/10.1210/en.2008-0602

31 Cork, D.M., Lennard, T.W. and Tyson-Capper, A.J. (2008) Alternative splicing and the progesterone receptor in breast cancer. Breast Cancer Res. 10, 207, https://doi.org/10.1186/bcr2097

32 Hirata, S., Shoda, T., Kato, J. and Hoshi, K. (2002) The novel exon, exon T, of the human progesterone receptor gene and the genomic organization of the gene. J. Steroid Biochem. Mol. Biol. 80, 365-367, https://doi.org/10.1016/S0960-0760(02)00019-5

33 Saner, K.J., Welter, B.H., Zhang, F., Hansen, E., Dupont, B., Wei, Y. et al. (2003) Cloning and expression of a novel, truncated, progesterone receptor. Mol. Cell. Endocrinol. 200, 155-163, https://doi.org/10.1016/S0303-7207(02)00380-5

34 Balleine, R.L., Hunt, S.M. and Clarke, C.L. (1999) Coexpression of alternatively spliced estrogen and progesterone receptor transcripts in human breast cancer. J. Clin. Endocrinol. Metab. 84, 1370-1377, https://doi.org/10.1210/jc.84.4.1370

35 Leygue, E., Dotzlaw, H., Watson, P.H. and Murphy, L.C. (1996) Identification of novel exon-deleted progesterone receptor variant mRNAs in human breast tissue. Biochem. Biophys. Res. Commun. 228, 63-68, https://doi.org/10.1006/bbrc.1996.1616

36 Richer, J.K., Lange, C.A., Wierman, A.M., Brooks, K.M., Tung, L., Takimoto, G.S. et al. (1998) Progesterone receptor variants found in breast cells repress transcription by wild-type receptors. Breast Cancer Res. Treat. 48, 231-241, https://doi.org/10.1023/A:1005941117247

37 Yeates, C., Hunt, S.M., Balleine, R.L. and Clarke, C.L. (1998) Characterization of a truncated progesterone receptor protein in breast tumors. J. Clin. Endocrinol. Metab. 83, 4600-4670, https://doi.org/10.1210/jc.83.2.460

38 Wei, L.L., Krett, N.L., Francis, M.D., Gordon, D.F., Wood, W.M., O’Malley, B.W. et al. (1988) Multiple human progesterone receptor messenger ribonucleic acids and their autoregulation by progestin agonists and antagonists in breast cancer cells. Mol. Endocrinol. 2, 62-72, https://doi.org/10.1210/mend-2-1-62

39 Springwald, A., Lattrich, C., Skrzypczak, M., Goerse, R., Ortmann, 0. and Treeck, 0. (2010) Identification of novel transcript variants of estrogen receptor alpha, beta and progesterone receptor gene in human endometrium. Endocrine 37, 415-424, https://doi.org/10.1007/s12020-010-9322-8

40 Wei, L.L. and Miner, R. (1994) Evidence for the existence of a third progesterone receptor protein in human breast cancer cell line T47D. Cancer Res. 54, 340-343

41 Giulianelli, S., Riggio, M., Guillardoy, T., Perez Pinero, C., Gorostiaga, M.A., Sequeira, G. et al. (2019) FGF2 induces breast cancer growth through ligand-independent activation and recruitment of ERalpha and PRBDelta4 isoform to MYC regulatory sequences. Int. J. Cancer 145, 1874-1888, https://doi.org/10.1002/ijc.32252

42 Macias, H. and Hinck, L. (2012) Mammary gland development. Wiley Interdiscip. Rev. Dev. Biol. 1, 533-557, https://doi.org/10.1002/wdev.35

43 Monteiro FL, D.I. and Helguero, L.A. (2020) Hormone Signaling pathways in the postnatal mammary gland. In Tissue-Specific Cell Signaling (Silva, J., Fretas, M. and Fardilha, M., eds), Springer, Cham, https://doi.org/10.1007/978-3-030-44436-5'10

44 Watson, C.J. and Khaled, W.T. (2020) Mammary development in the embryo and adult: new insights into the journey of morphogenesis and commitment. Development 147, dev169862, https://doi.org/10.1242/dev.169862

45 Brisken, C., Hess, K. and Jeitziner, R. (2015) Progesterone and overlooked endocrine pathways in breast cancer pathogenesis. Endocrinology 156 3442-3450, https://doi.org/10.1210/en.2015-1392

46 Kariagina, A., Aupperlee, M.D. and Haslam, S.Z. (2008) Progesterone receptor isoform functions in normal breast development and breast cancer. Crit. Rev. Eukaryot. Gene Expr. 18, 11-33, https://doi.org/10.1615/CritRevEukarGeneExpr.v18.i1.20 
47 Aupperlee, M.D., Smith, K.T., Kariagina, A. and Haslam, S.Z. (2005) Progesterone Receptor Isoforms A and B: Temporal and Spatial Differences in Expression During Murine Mammary Gland Development. Endocrinology 146, 3577-3588, https://doi.org/10.1210/en.2005-0346

48 Brisken, C. and Scabia, V. (2020) 90 YEARS OF PROGESTERONE: Progesterone receptor signaling in the normal breast and its implications for cancer. J. Mol. Endocrinol. 65, T81-T94, https://doi.org/10.1530/JME-20-0091

49 Trabert, B., Sherman, M.E., Kannan, N. and Stanczyk, F.Z. (2020) Progesterone and breast cancer. Endocr. Rev. 41, 320-344, https://doi.org/10.1210/endrev/bnz001

50 Cenciarini, M.E. and Proietti, C.J. (2019) Molecular mechanisms underlying progesterone receptor action in breast cancer: Insights into cell proliferation and stem cell regulation. Steroids 152, 108503, https://doi.org/10.1016/j.steroids.2019.108503

51 Lamb, C.A., Fabris, V.T. and Lanari, C. (2020) Progesterone and breast. Best Pract. Res. Clin. Obstet. Gynaecol. 69, 85-94, https://doi.org/10.1016/j.bpobgyn.2020.04.001

52 Lamb, C.A., Fabris, V.T., Jacobsen, B., Molinolo, A.A. and Lanari, C. (2018) Biological and clinical impact of imbalanced progesterone receptor isoform ratios in breast cancer. Endocr. Relat. Cancer 10, https://doi.org/10.1530/ERC-18-0179

53 Sathyamoorthy, N. and Lange, C.A. (2020) Progesterone and breast cancer: an NCI Workshop Report. Horm Cancer 11, 1-12, https://doi.org/10.1007/s12672-020-00379-1

54 Brisken, C. and O'Malley, B. (2010) Hormone action in the mammary gland. Cold Spring Harb. Perspect. Biol. 2, a003178, https://doi.org/10.1101/cshperspect.a003178

55 Holliday, H., Baker, L.A., Junankar, S.R., Clark, S.J. and Swarbrick, A. (2018) Epigenomics of mammary gland development. Breast Cancer Res. 20, 100, https://doi.org/10.1186/s13058-018-1031-x

56 Pal, B., Bouras, T., Shi, W., Vaillant, F., Sheridan, J.M., Fu, N. et al. (2013) Global changes in the mammary epigenome are induced by hormonal cues and coordinated by Ezh2. Cell Rep. 3, 411-426, https://doi.org/10.1016/j.celrep.2012.12.020

57 Avgustinova, A. and Benitah, S.A. (2016) Epigenetic control of adult stem cell function. Nat. Rev. Mol. Cell Biol. 17, 643-658, https://doi.org/10.1038/nrm.2016.76

58 Michalak, E.M., Nacerddine, K., Pietersen, A., Beuger, V., Pawlitzky, I., Cornelissen-Steijger, P. et al. (2013) Polycomb group gene Ezh2 regulates mammary gland morphogenesis and maintains the luminal progenitor pool. Stem Cells 31, 1910-1920, https://doi.org/10.1002/stem.1437

59 Zou, M.R., Cao, J., Liu, Z., Huh, S.J., Polyak, K. and Yan, Q. (2014) Histone demethylase jumonji AT-rich interactive domain 1B (JARID1B) controls mammary gland development by regulating key developmental and lineage specification genes. J. Biol. Chem. 289, 17620-17633, https://doi.org/10.1074/jbc.M114.570853

60 Clarke, R.B., Howell, A., Potten, C.S. and Anderson, E. (1997) Dissociation between steroid receptor expression and cell proliferation in the human breast. Cancer Res. 57, 4987-4991

61 Seagroves, T.N., Lydon, J.P., Hovey, R.C., Vonderhaar, B.K. and Rosen, J.M. (2000) C/EBPbeta (CCAAT/enhancer binding protein) controls cell fate determination during mammary gland development. Mol. Endocrinol. 14, 359-368

62 Russo, J., Ao, X., Grill, C. and Russo, I.H. (1999) Pattern of distribution of cells positive for estrogen receptor alpha and progesterone receptor in relation to proliferating cells in the mammary gland. Breast Cancer Res. Treat. 53, 217-227, https://doi.org/10.1023/A:1006186719322

63 Brisken, C. and Duss, S. (2007) Stem cells and the stem cell niche in the breast: an integrated hormonal and developmental perspective. Stem Cell Rev. 3, 147-156, https://doi.org/10.1007/s12015-007-0019-1

64 Fata, J.E., Kong, Y.Y., Li, J., Sasaki, T., Irie-Sasaki, J., Moorehead, R.A. et al. (2000) The osteoclast differentiation factor osteoprotegerin-ligand is essential for mammary gland development. Cell 103, 41-50, https://doi.org/10.1016/S0092-8674(00)00103-3

65 Cao, Y., Bonizzi, G., Seagroves, T.N., Greten, F.R., Johnson, R., Schmidt, E.V. et al. (2001) IKKalpha provides an essential link between RANK signaling and cyclin D1 expression during mammary gland development. Cell 107, 763-775, https://doi.org/10.1016/S0092-8674(01)00599-2

66 Mulac-Jericevic, B., Lydon, J.P., DeMayo, F.J. and Conneely, 0.M. (2003) Defective mammary gland morphogenesis in mice lacking the progesterone receptor B isoform. Proc. Natl. Acad. Sci. U. S. A. 100, 9744-9749, https://doi.org/10.1073/pnas.1732707100

67 Joshi, P.A., Waterhouse, P.D., Kannan, N., Narala, S., Fang, H., Di Grappa, M.A. et al. (2015) RANK Signaling Amplifies WNT-Responsive Mammary Progenitors through R-SPONDIN1. Stem Cell Rep. 5, 31-44, https://doi.org/10.1016/j.stemcr.2015.05.012

68 Asselin-Labat, M.L., Vaillant, F., Sheridan, J.M., Pal, B., Wu, D., Simpson, E.R. et al. (2010) Control of mammary stem cell function by steroid hormone signalling. Nature 465, 798-802, https://doi.org/10.1038/nature09027

69 Joshi, P.A., Jackson, H.W., Beristain, A.G., Di Grappa, M.A., Mote, P.A., Clarke, C.L. et al. (2010) Progesterone induces adult mammary stem cell expansion. Nature 465, 803-807, https://doi.org/10.1038/nature09091

70 Brisken, C., Heineman, A., Chavarria, T., Elenbaas, B., Tan, J., Dey, S.K. et al. (2000) Essential function of Wnt-4 in mammary gland development downstream of progesterone signaling. Genes Dev. 14, 650-654

71 Ismail, P.M., DeMayo, F.J., Amato, P. and Lydon, J.P. (2004) Progesterone induction of calcitonin expression in the murine mammary gland. J. Endocrinol. 180, 287-295, https://doi.org/10.1677/joe.0.1800287

72 Aupperlee, M.D., Leipprandt, J.R., Bennett, J.M., Schwartz, R.C. and Haslam, S.Z. (2013) Amphiregulin mediates progesterone-induced mammary ductal development during puberty. Breast Cancer Res. 15, R44, https://doi.org/10.1186/bcr3431

73 Shiah, Y.J., Tharmapalan, P., Casey, A.E., Joshi, P.A., McKee, T.D., Jackson, H.W. et al. (2015) A Progesterone-CXCR4 Axis Controls Mammary Progenitor Cell Fate in the Adult Gland. Stem Cell Rep. 4, 313-322, https://doi.org/10.1016/j.stemcr.2015.01.011

74 Dong, J., Huang, S., Caikovski, M., Ji, S., McGrath, A., Custorio, M.G. et al. (2011) ID4 regulates mammary gland development by suppressing p38MAPK activity. Development 138, 5247-5256, https://doi.org/10.1242/dev.069203

75 Ataca, D., Aouad, P., Constantin, C., Laszlo, C., Beleut, M., Shamseddin, M. et al. (2020) The secreted protease Adamts18 links hormone action to activation of the mammary stem cell niche. Nat. Com. 11, 1571, https://doi.org/10.1038/s41467-020-15357-y 
76 Hilton, H.N., Clarke, C.L. and Graham, J.D. (2018) Estrogen and progesterone signalling in the normal breast and its implications for cancer development. Mol. Cell. Endocrinol. 466, 2-14, https://doi.org/10.1016/j.mce.2017.08.011

77 Rajaram, R.D., Buric, D., Caikovski, M., Ayyanan, A., Rougemont, J., Shan, J. et al. (2015) Progesterone and Wnt4 control mammary stem cells via myoepithelial crosstalk. EMBO J. 34, 641-652, https://doi.org/10.15252/embj.201490434

78 Beleut, M., Rajaram, R.D., Caikovski, M., Ayyanan, A., Germano, D., Choi, Y. et al. (2010) Two distinct mechanisms underlie progesterone-induced proliferation in the mammary gland. Proc. Natl. Acad. Sci. U. S. A. 107, 2989-2994, https://doi.org/10.1073/pnas.0915148107

79 Lydon, J.P., DeMayo, F.J., Funk, C.R., Mani, S.K., Hughes, A.R., Montgomery, Jr, C.A. et al. (1995) Mice lacking progesterone receptor exhibit pleiotropic reproductive abnormalities. Genes Dev. 9, 2266-2278, https://doi.org/10.1101/gad.9.18.2266

80 Conneely, 0.M., Mulac-Jericevic, B. and Lydon, J.P. (2003) Progesterone-dependent regulation of female reproductive activity by two distinct progesterone receptor isoforms. Steroids 68, 771-778, https://doi.org/10.1016/S0039-128X(03)00126-0

81 Shyamala, G., Yang, X., Silberstein, G., Barcellos-Hoff, M.H. and Dale, E. (1998) Transgenic mice carrying an imbalance in the native ratio of A to B forms of progesterone receptor exhibit developmental abnormalities in mammary glands. Proc. Natl. Acad. Sci. U.S.A. 95, 696-701, https://doi.org/10.1073/pnas.95.2.696

82 Simian, M., Bissell, M.J., Barcellos-Hoff, M.H. and Shyamala, G. (2009) Estrogen and progesterone receptors have distinct roles in the establishment of the hyperplastic phenotype in PR-A transgenic mice. Breast Cancer Res. 11, R72, https://doi.org/10.1186/bcr2408

83 Shyamala, G., Yang, X., Cardiff, R.D. and Dale, E. (2000) Impact of progesterone receptor on cell-fate decisions during mammary gland development. Proc. Natl. Acad. Sci. U.S.A. 97, 3044-3049, https://doi.org/10.1073/pnas.97.7.3044

84 Recouvreux, M.S., Diaz Bessone, M.I., Taruselli, A., Todaro, L., Lago Huvelle, M.A., Sampayo, R.G. et al. (2020) Alterations in progesterone receptor isoform balance in normal and neoplastic breast cells modulates the stem cell population. Cells 9, 2074, https://doi.org/10.3390/cells9092074

85 Graham, J.D., Mote, P.A., Salagame, U., van Dijk, J.H., Balleine, R.L., Huschtscha, L.I. et al. (2009) DNA replication licensing and progenitor numbers are increased by progesterone in normal human breast. Endocrinology 150, 3318-3326, https://doi.org/10.1210/en.2008-1630

86 Montero, G.G., Vanzulli, S.I., Cerliani, J.P., Bottino, M.C., Bolado, J., Vela, J. et al. (2007) Association of estrogen receptor alpha and progesterone receptor A expression with hormonal mammary carcinogenesis: role of the host microenvironment. Breast Cancer Res. 9, R22, https://doi.org/10.1186/bcr1660

87 Aupperlee, M.D., Drolet, A.A., Durairaj, S., Wang, W., Schwartz, R.C. and Haslam, S.Z. (2009) Strain-specific differences in the mechanisms of progesterone regulation of murine mammary gland development. Endocrinology 150, 1485-1494, https://doi.org/10.1210/en.2008-1459

88 Chenlo, M., Aliyev, E., Rodrigues, J.S., Vieiro-Balo, P., Blanco Freire, M.N., Cameselle-Teijeiro, J.M. et al. (2020) Sequential colocalization of ERa, PR, and AR hormone receptors using confocal microscopy enables new insights into normal breast and prostate tissue and cancers. Cancers 12, 3591, https://doi.org/10.3390/cancers12123591

89 Conde, I., Paniagua, R., Fraile, B., Lucio, J. and Arenas, M.I. (2008) Glucocorticoid receptor changes its cellular location with breast cancer development. Histol. Histopathol. 23, 77-85

90 Buxant, F., Engohan-Aloghe, C. and Noel, J.C. (2010) Estrogen receptor, progesterone receptor, and glucocorticoid receptor expression in normal breast tissue, breast in situ carcinoma, and invasive breast cancer. Appl. Immunohistochem. Mol. Morphol.: AIMM 18, 254-257, https://doi.org/10.1097/PAl.0b013e3181c10180

91 Giulianelli, S., Molinolo, A. and Lanari, C. (2013) Targeting progesterone receptors in breast cancer. Vitam. Horm. 93, 161-184, https://doi.org/10.1016/B978-0-12-416673-8.00009-5

92 Kordon, E.C., Molinolo, A.A., Pasqualini, C.D., Charreau, E.H., Pazos, P., Dran, G. et al. (1993) Progesterone induction of mammary carcinomas in $\mathrm{BALB} / \mathrm{c}$ female mice. Correlation between progestin dependence and morphology. Breast Cancer Res. Treat. 28, 29-39, https://doi.org/10.1007/BF00666353

93 Teulings, F.A., van Gilse, H.A., Henkelman, M.S., Portengen, H. and Alexieva-Figusch, J. (1980) Estrogen, androgen, glucocorticoid, and progesterone receptors in progestin-induced regression of human breast cancer. Cancer Res. 40, 2557-2561

94 Lanari, C., Molinolo, A.A. and Pasqualini, C.D. (1986) Induction of mammary adenocarcinomas by medroxyprogesterone acetate in BALB/c female mice. Cancer Lett. 33, 215-223, https://doi.org/10.1016/0304-3835(86)90027-3

95 Molinolo, A., Simian, M., Vanzulli, S., Pazos, P., Lamb, C. and Lanari, C. (1998) Involvement of EGF in medroxyprogesterone acetate (MPA)-induced mammary gland hyperplasia and its role in MPA-induced mammary tumors in BALB/c mice. Cancer Lett. 126, 49-57, https://doi.org/10.1016/S0304-3835(97)00527-2

96 Kordon, E.C., Guerra, F., Molinolo, A.A., Charreau, E.H., Pasqualini, C.D., Pazos, P. et al. (1994) Effect of sialoadenectomy on medroxyprogesterone-acetate-induced mammary carcinogenesis in BALB/c mice. Correlation between histology and epidermal-growth-factor receptor content. Int. J. Cancer 59, 196-203, https://doi.org/10.1002/ijc.2910590210

97 Lydon, J.P., Ge, G., Kittrell, F.S., Medina, D. and O'Malley, B.W. (1999) Murine mammary gland carcinogenesis is critically dependent on progesterone receptor function. Cancer Res. 59, 4276-4284

98 Poole, A.J., Li, Y., Kim, Y., Lin, S.C., Lee, W.H. and Lee, E.Y. (2006) Prevention of Brca1-mediated mammary tumorigenesis in mice by a progesterone antagonist. Science 314, 1467-1470, https://doi.org/10.1126/science.1130471

99 Gonzalez-Suarez, E., Jacob, A.P., Jones, J., Miller, R., Roudier-Meyer, M.P., Erwert, R. et al. (2010) RANK ligand mediates progestin-induced mammary epithelial proliferation and carcinogenesis. Nature 468, 103-107, https://doi.org/10.1038/nature09495

100 Schramek, D., Leibbrandt, A., Sigl, V., Kenner, L., Pospisilik, J.A., Lee, H.J. et al. (2010) Osteoclast differentiation factor RANKL controls development of progestin-driven mammary cancer. Nature 468, 98-102, https://doi.org/10.1038/nature09387

101 Stevenson, J.C., Rozenberg, S., Maffei, S., Egarter, C., Stute, P. and Romer, T. (2020) Progestogens as a component of menopausal hormone therapy: the right molecule makes the difference. Drugs Context. 9, 1-12, https://doi.org/10.7573/dic.2020-10-1 
102 Busund, M., Bugge, N.S., Braaten, T., Waaseth, M., Rylander, C. and Lund, E. (2018) Progestin-only and combined oral contraceptives and receptor-defined premenopausal breast cancer risk: The Norwegian Women and Cancer Study. Int. J. Cancer 142, 2293-2302, https://doi.org/10.1002/ijc.31266

103 Collaborative Group on Hormonal Factors in Breast C (2019) Type and timing of menopausal hormone therapy and breast cancer risk: individual participant meta-analysis of the worldwide epidemiological evidence. Lancet 394, 1159-1168, https://doi.org/10.1016/S0140-6736(19)31709-X

104 Horwitz, K.B. and Sartorius, C.A. (2020) 90 YEARS OF PROGESTERONE: progesterone and progesterone receptors in breast cancer: past, present, future. J. Mol. Endocr. 65, T49-T63, https://doi.org/10.1530/JME-20-0104

105 Hipolito Rodrigues, M.A. and Gompel, A. (2021) Micronized progesterone, progestins, and menopause hormone therapy. Women Health 61, 3-14, https://doi.org/10.1080/03630242.2020.1824956

106 Kiss, R., Paridaens, R.J., Heuson, J.C. and Danguy, A.J. (1986) Effect of progesterone on cell proliferation in the MXT mouse hormone-sensitive mammary neoplasm. J. Natl. Cancer Inst. 77, 173-178

107 Nishino, Y., Schneider, M.R. and Michna, H. (1994) Enhancement of the antitumor efficacy of the antiprogestin, onapristone, by combination with the antiestrogen, ICl 164384. J. Cancer Res. Clin. Oncol. 120, 298-302, https://doi.org/10.1007/BF01236387

108 Molinolo, A.A., Lanari, C., Charreau, E.H., Sanjuan, N. and Pasqualini, C.D. (1987) Mouse mammary tumors induced by medroxyprogesterone acetate: immunohistochemistry and hormonal receptors. J. Natl. Cancer Inst. 79, 1341-1350

109 Kordon, E., Lanari, C., Meiss, R., Charreau, E. and Pasqualini, C.D. (1990) Hormone dependence of a mouse mammary tumor line induced in vivo by medroxyprogesterone acetate. Breast Cancer Res. Treat. 17, 33-43, https://doi.org/10.1007/BF01812682

110 Montecchia, M.F., Lamb, C., Molinolo, A.A., Luthy, I.A., Pazos, P., Charreau, E. et al. (1999) Progesterone receptor involvement in independent tumor growth in MPA-induced murine mammary adenocarcinomas. J. Steroid Biochem. Mol. Biol. 68, 11-21, https://doi.org/10.1016/S0960-0760(98)00166-6

111 Helguero, L.A., Viegas, M., Asaithamby, A., Shyamala, G., Lanari, C. and Molinolo, A.A. (2003) Progesterone receptor expression in medroxyprogesterone acetate-induced murine mammary carcinomas and response to endocrine treatment. Breast Cancer Res. Treat. 79, 379-390, https://doi.org/10.1023/A:1024029826248

112 Wargon, V., Helguero, L.A., Bolado, J., Rojas, P., Novaro, V., Molinolo, A. et al. (2009) Reversal of antiprogestin resistance and progesterone receptor isoform ratio in acquired resistant mammary carcinomas. Breast Cancer Res. Treat. 116, 449-460, https://doi.org/10.1007/s10549-008-0150-y

113 Wargon, V., Riggio, M., Giulianelli, S., Sequeira, G.R., Rojas, P., May, M. et al. (2015) Progestin and antiprogestin responsiveness in breast cancer is driven by the PRA/PRB ratio via AIB1 or SMRT recruitment to the CCND1 and MYC promoters. Int. J. Cancer 136, 2680-2692, https://doi.org/10.1002/ijc.29304

114 Lamb, C.A., Helguero, L.A., Giulianelli, S., Soldati, R., Vanzulli, S.I., Molinolo, A. et al. (2005) Antisense oligonucleotides targeting the progesterone receptor inhibit hormone-independent breast cancer growth in mice. Breast Cancer Res. 7, R1111-R1121, https://doi.org/10.1186/bcr1345

115 Giulianelli, S., Herschkowitz, J.I., Patel, V., Lamb, C.A., Gutkind, J.S., Molinolo, A. et al. (2011) MPA-induced gene expression and stromal and parenchymal gene expression profiles in luminal murine mammary carcinomas with different hormonal requirements. Breast Cancer Res. Treat. 129, 49-67, https://doi.org/10.1007/s10549-010-1185-4

116 Giulianelli, S., Cerliani, J.P., Lamb, C.A., Fabris, V.T., Bottino, M.C., Gorostiaga, M.A. et al. (2008) Carcinoma-associated fibroblasts activate progesterone receptors and induce hormone independent mammary tumor growth: a role for the FGF-2/FGFR-2 axis. Int. J. Cancer 123, 2518-2531, https://doi.org/10.1002/ijc.23802

117 Cerliani, J.P., Guillardoy, T., Giulianelli, S., Vaque, J.P., Gutkind, J.S., Vanzulli, S.I. et al. (2011) Interaction between FGFR-2, STAT5, and progesterone receptors in breast cancer. Cancer Res. 71, 3720-3731, https://doi.org/10.1158/0008-5472.CAN-10-3074

118 DiGiacomo, J.W., Godet, I., Trautmann-Rodriguez, M. and Gilkes, D.M. (2021) Extracellular matrix-bound FGF2 mediates estrogen receptor signaling and therapeutic response in breast cancer. Mol. Cancer Res. 19, 136-149, https://doi.org/10.1158/1541-7786.MCR-20-0554

119 Wargon, V., Fernandez, S.V., Goin, M., Giulianelli, S., Russo, J. and Lanari, C. (2011) Hypermethylation of the progesterone receptor A in constitutive antiprogestin-resistant mouse mammary carcinomas. Breast Cancer Res. Treat. 126, 319-332, https://doi.org/10.1007/s10549-010-0908-X

120 Sahores, A., Figueroa, V., May, M., Liguori, M., Rubstein, A., Fuentes, C. et al. (2018) Increased high molecular weight FGF2 in endocrine-resistant breast cancer. Horm Cancer 9, 338-348, https://doi.org/10.1007/s12672-018-0339-4

121 Shen, T., Horwitz, K.B. and Lange, C.A. (2001) Transcriptional hyperactivity of human progesterone receptors is coupled to their ligand-dependent down-regulation by mitogen-activated protein kinase-dependent phosphorylation of serine 294. Mol. Cell. Biol. 21, 6122-6131, https://doi.org/10.1128/MCB.21.18.6122-6131.2001

122 Lange, C.A., Shen, T. and Horwitz, K.B. (2000) Phosphorylation of human progesterone receptors at serine-294 by mitogen-activated protein kinase signals their degradation by the $26 \mathrm{~S}$ proteasome. Proc. Natl. Acad. Sci. U. S. A. 97, 1032-1037, https://doi.org/10.1073/pnas.97.3.1032

123 Cagnet, S., Ataca, D., Sflomos, G., Aouad, P., Schuepbach-Mallepell, S., Hugues, H. et al. (2018) Oestrogen receptor alpha AF-1 and AF-2 domains have cell population-specific functions in the mammary epithelium. Nat. Com. 9, 4723, https://doi.org/10.1038/s41467-018-07175-0

124 Sequeira, G., Vanzulli, S.I., Rojas, P., Lamb, C., Colombo, L., May, M. et al. (2014) The effectiveness of nano chemotherapeutic particles combined with mifepristone depends on the PR isoform ratio in preclinical models of breast cancer. Oncotarget 5, 3246-3260, https://doi.org/10.18632/oncotarget.1922

125 Sequeira, G.R., Sahores, A., Dalotto-Moreno, T., Perrotta, R.M., Pataccini, G., Vanzulli, S.I. et al. (2020) Enhanced antitumor immunity via endocrine therapy prevents mammary tumor relapse and increases immune checkpoint blockade sensitivity. Cancer Res. 81, 1375-1387, https://doi.org/10.1158/0008-5472.CAN-20-1441

126 Hosseini, H., Obradovic, M.M.S., Hoffmann, M., Harper, K.L., Sosa, M.S., Werner-Klein, M. et al. (2016) Early dissemination seeds metastasis in breast cancer. Nature 540, 552-558, https://doi.org/10.1038/nature20785 
127 Bakker, G.H., Setyono-Han, B., Henkelman, M.S., de Jong, F.H., Lamberts, S.W., van der Schoot, P. et al. (1987) Comparison of the actions of the antiprogestin mifepristone (RU486), the progestin megestrol acetate, the LHRH analog buserelin, and ovariectomy in treatment of rat mammary tumors. Cancer Treat. Rep. 71, 1021-1027

128 Bakker, G.H., Setyono-Han, B., Portengen, H., de Jong, F.H., Foekens, J.A. and Klijn, J.G. (1989) Endocrine and antitumor effects of combined treatment with an antiprogestin and antiestrogen or luteinizing hormone-releasing hormone agonist in female rats bearing mammary tumors. Endocrinology 125, 1593-1598, https://doi.org/10.1210/endo-125-3-1593

129 Kloosterboer, H.J., Deckers, G.H., Schoonen, W.G., Hanssen, R.G., Rose, U.M., Verbost, P.M. et al. (2000) Preclinical experience with two selective progesterone receptor modulators on breast and endometrium. Steroids 65, 733-740, https://doi.org/10.1016/S0039-128X(00)00189-6

130 Wiehle, R.D., Christov, K. and Mehta, R. (2007) Anti-progestins suppress the growth of established tumors induced by 7,12-dimethylbenz(a)anthracene: comparison between RU486 and a new 21-substituted-19-nor-progestin. Oncol. Rep. 18, 167-174, https://doi.org/10.3892/or.18.1.167

131 Nishino, T., Ishibashi, K., Hirtreiter, C. and Nishino, Y. (2009) Potentiation of the antitumor effect of tamoxifen by combination with the antiprogestin onapristone. J. Steroid Biochem. Mol. Biol. 116, 187-190, https://doi.org/10.1016/j.jsbmb.2009.05.013

132 Michna, H., Schneider, M.R., Nishino, Y. and el Etreby, M.F. (1989) Antitumor activity of the antiprogestins ZK 98.299 and RU 38.486 in hormone dependent rat and mouse mammary tumors: mechanistic studies. Breast Cancer Res. Treat. 14, 275-288, https://doi.org/10.1007/BF01806299

133 Diep, C.H., Daniel, A., Mauro, L., Knutson, T. and Lange, C. (2015) Progesterone action in breast, uterine, and ovarian cancers. J. Mol. Endocrinol. 54, R31-R53, https://doi.org/10.1530/JME-14-0252

134 Truong, T.H. and Lange, C.A. (2018) Deciphering steroid receptor crosstalk in hormone-driven cancers. Endocrinology 159, 3897-3907, https://doi.org/10.1210/en.2018-00831

135 Giulianelli, S., Vaque, J.P., Soldati, R., Wargon, V., Vanzulli, S.I., Martins, R. et al. (2012) Estrogen receptor alpha mediates progestin-induced mammary tumor growth by interacting with progesterone receptors at the cyclin D1/MYC promoters. Cancer Res. 72, 2416-2427, https://doi.org/10.1158/0008-5472.CAN-11-3290

136 Daniel, A.R., Gaviglio, A.L., Knutson, T.P., Ostrander, J.H., D’Assoro, A.B., Ravindranathan, P. et al. (2015) Progesterone receptor-B enhances estrogen responsiveness of breast cancer cells via scaffolding P. Oncogene 34, 506-515, https://doi.org/10.1038/onc.2013.579

137 Mohammed, H., Russell, I.A., Stark, R., Rueda, 0.M., Hickey, T.E., Tarulli, G.A. et al. (2015) Progesterone receptor modulates ERalpha action in breast cancer. Nature 523, 313-317, https://doi.org/10.1038/nature14583

138 Sartorius, C.A., Harvell, D.M., Shen, T. and Horwitz, K.B. (2005) Progestins initiate a luminal to myoepithelial switch in estrogen-dependent human breast tumors without altering growth. Cancer Res. 65, 9779-9788, https://doi.org/10.1158/0008-5472.CAN-05-0505

139 Liang, Y., Besch-Williford, C., Brekken, R.A. and Hyder, S.M. (2007) Progestin-dependent progression of human breast tumor xenografts: a novel model for evaluating antitumor therapeutics. Cancer Res. 67, 9929-9936, https://doi.org/10.1158/0008-5472.CAN-07-1103

140 Singhal, H., Greene, M.E., Tarulli, G., Zarnke, A.L., Bourgo, R.J., Laine, M. et al. (2016) Genomic agonism and phenotypic antagonism between estrogen and progesterone receptors in breast cancer. Sci. Adv. 2, e1501924, https://doi.org/10.1126/sciadv.1501924

141 el Etreby, M.F. and Liang, Y. (1998) Effect of antiprogestins and tamoxifen on growth inhibition of MCF-7 human breast cancer cells in nude mice. Breast Cancer Res. Treat. 49, 109-117, https://doi.org/10.1023/A:1006098910000

142 Singhal, H., Greene, M.E., Zarnke, A.L., Laine, M., Al Abosy, R., Chang, Y.F. et al. (2018) Progesterone receptor isoforms, agonists and antagonists differentially reprogram estrogen signaling. Oncotarget 9, 4282-4300, https://doi.org/10.18632/oncotarget.21378

143 Dong, J., Grunstein, J., Tejada, M., Peale, F., Frantz, G., Liang, W.C. et al. (2004) VEGF-null cells require PDGFR alpha signaling-mediated stromal fibroblast recruitment for tumorigenesis. EMBO J. 23, 2800-2810, https://doi.org/10.1038/sj.emboj.7600289

144 Ruan, X., Gu, M., Cai, G., Zhao, Y., Wang, L., Li, X. et al. (2019) Progestogens and PGRMC1-dependent breast cancer tumor growth: an in-vitro and xenograft study. Maturitas 123, 1-8, https://doi.org/10.1016/j.maturitas.2019.01.015

145 Zhao, Y., Ruan, X., Wang, H., Li, X., Gu, M., Wang, L. et al. (2017) The presence of a membrane-bound progesterone receptor induces growth of breast cancer with norethisterone but not with progesterone: A xenograft model. Maturitas 102, 26-33, https://doi.org/10.1016/j.maturitas.2017.05.007

146 Sartorius, C.A., Shen, T. and Horwitz, K.B. (2003) Progesterone receptors A and B differentially affect the growth of estrogen-dependent human breast tumor xenografts. Breast Cancer Res. Treat. 79, 287-299, https://doi.org/10.1023/A:1024031731269

147 Cittelly, D.M., Finlay-Schultz, J., Howe, E.N., Spoelstra, N.S., Axlund, S.D., Hendricks, P. et al. (2013) Progestin suppression of miR-29 potentiates dedifferentiation of breast cancer cells via KLF4. Oncogene 32, 2555-2564, https://doi.org/10.1038/onc.2012.275

148 Horwitz, K.B., Dye, W.W., Harrell, J.C., Kabos, P. and Sartorius, C.A. (2008) Rare steroid receptor-negative basal-like tumorigenic cells in luminal subtype human breast cancer xenografts. Proc. Natl. Acad. Sci. U. S. A. 105, 5774-5779, https://doi.org/10.1073/pnas.0706216105

149 Kabos, P., Haughian, J.M., Wang, X., Dye, W.W., Finlayson, C., Elias, A. et al. (2011) Cytokeratin 5 positive cells represent a steroid receptor negative and therapy resistant subpopulation in luminal breast cancers. Breast Cancer Res. Treat. 128, 45-55, https://doi.org/10.1007/s10549-010-1078-6

150 Axlund, S.D. and Sartorius, C.A. (2012) Progesterone regulation of stem and progenitor cells in normal and malignant breast. Mol. Cell. Endocrinol. 357, 71-79, https://doi.org/10.1016/j.mce.2011.09.021

151 Goodman, C.R., Sato, T., Peck, A.R., Girondo, M.A., Yang, N., Liu, C. et al. (2016) Steroid induction of therapy-resistant cytokeratin-5-positive cells in estrogen receptor-positive breast cancer through a BCL6-dependent mechanism. Oncogene 35, 1373-1385, https://doi.org/10.1038/onc.2015.193

152 McGinn, 0., Ward, A.V., Fettig, L.M., Riley, D., Ivie, J., Paul, K.V. et al. (2020) Cytokeratin 5 alters beta-catenin dynamics in breast cancer cells. Oncogene 39, 2478-2492, https://doi.org/10.1038/s41388-020-1164-0

153 Knutson, T.P., Truong, T.H., Ma, S., Brady, N.J., Sullivan, M.E., Raj, G. et al. (2017) Posttranslationally modified progesterone receptors direct ligand-specific expression of breast cancer stem cell-associated gene programs. J. Hematol. Oncol. 10, 89, https://doi.org/10.1186/s13045-017-0462-7 
154 Truong, T.H., Dwyer, A.R., Diep, C.H., Hu, H., Hagen, K.M. and Lange, C.A. (2019) Phosphorylated progesterone receptor isoforms mediate opposing stem cell and proliferative breast cancer cell fates. Endocrinology 160, 430-446, https://doi.org/10.1210/en.2018-00990

155 Rojas, P.A., May, M., Sequeira, G.R., Elia, A., Alvarez, M., Martinez, P. et al. (2017) Progesterone receptor isoform ratio: a breast cancer prognostic and predictive factor for antiprogestin responsiveness. J. Natl. Cancer Inst. 109, djw317, https://doi.org/10.1093/jnci/djw317

156 Brunner, N., Spang-Thomsen, M., Skovgaard, P.H., Engelholm, S.A., Nielsen, A. and Vindelov, L. (1985) Endocrine sensitivity of the receptor-positive T61 human breast carcinoma serially grown in nude mice. Int. J. Cancer 35, 59-64, https://doi.org/10.1002/ijc.2910350110

157 Schneider, M.R., Michna, H., Habenicht, U.F., Nishino, Y., Grill, H.J. and Pollow, K. (1992) The tumour-inhibiting potential of the progesterone antagonist Onapristone in the human mammary carcinoma T61 in nude mice. J. Cancer Res. Clin. Oncol. 118, 187-189, https://doi.org/10.1007/BF01410132

158 Finlay-Schultz, J., Gillen, A.E., Brechbuhl, H.M., Ivie, J.J., Matthews, S.B., Jacobsen, B.M. et al. (2017) Breast cancer suppression by progesterone receptors is mediated by their modulation of estrogen receptors and RNA polymerase III. Cancer Res. 77, 4934-4946, https://doi.org/10.1158/0008-5472.CAN-16-3541

159 Esber, N., Cherbonnier, C., Resche-Rigon, M., Hamze, A., Alami, M., Fagart, J. et al. (2016) Anti-tumoral effects of anti-progestins in a patient-derived breast cancer Xenograft model. Horm Cancer 7, 137-147, https://doi.org/10.1007/s12672-016-0255-4

160 Fiche, M., Scabia, V., Aouad, P., Battista, L., Treboux, A., Stravodimou, A. et al. (2019) Intraductal patient-derived xenografts of estrogen receptor alpha-positive breast cancer recapitulate the histopathological spectrum and metastatic potential of human lesions. J. Pathol. 247, 287-292, https://doi.org/10.1002/path.5200

161 Waks, A.G. and Winer, E.P. (2019) Breast cancer treatment: a review. JAMA 321, 288-300, https://doi.org/10.1001/jama.2018.19323

162 Cui, X., Schiff, R., Arpino, G., Osborne, C.K. and Lee, A.V. (2005) Biology of progesterone receptor loss in breast cancer and its implications for endocrine therapy. J. Clin. Oncol. 23, 7721-7735, https://doi.org/10.1200/JC0.2005.09.004

163 Cochrane, D.R., Bernales, S., Jacobsen, B.M., Cittelly, D.M., Howe, E.N., D’Amato, N.C. et al. (2014) Role of the androgen receptor in breast cancer and preclinical analysis of enzalutamide. Breast Cancer Res. 16, R7, https://doi.org/10.1186/bcr3599

164 Hickey, T.E., Selth, L.A., Chia, K.M., Laven-Law, G., Milioli, H.H., Roden, D. et al. (2021) The androgen receptor is a tumor suppressor in estrogen receptor-positive breast cancer. Nat. Med., https://doi.org/10.1038/s41591-020-01168-7

165 Garcia, X., Elia, A., Galizzi, L., May, M., Spengler, E., Martinez Vazquez, P. et al. (2020) Increased androgen receptor expression in estrogen receptor-positive/progesterone receptor-negative breast cancer. Breast Cancer Res. Treat. 180, 257-263, https://doi.org/10.1007/s10549-020-05527-3

166 Lamb, C.A., Vanzulli, S.I. and Lanari, C. (2019) Hormone receptors in breast cancer: more than estrogen receptors. Medicina (B. Aires). 79, 540-545

167 Bottino, M.C., Cerliani, J.P., Rojas, P., Giulianelli, S., Soldati, R., Mondillo, C. et al. (2011) Classical membrane progesterone receptors in murine mammary carcinomas: agonistic effects of progestins and RU-486 mediating rapid non-genomic effects. Breast Cancer Res. Treat. 126, 621-636, https://doi.org/10.1007/s10549-010-0971-3

168 Fabris, V., Abascal, M.F., Giulianelli, S., May, M., Sequeira, G.R., Jacobsen, B. et al. (2017) Isoform specificity of progesterone receptor antibodies. J. Pathol. Clin. Res. 3, 227-233, https://doi.org/10.1002/cjp2.83

169 Graham, J.D., Yeates, C., Balleine, R.L., Harvey, S.S., Milliken, J.S., Bilous, A.M. et al. (1995) Characterization of progesterone receptor A and B expression in human breast cancer. Cancer Res. 55, 5063-5068

170 Mote, P.A., Bartow, S., Tran, N. and Clarke, C.L. (2002) Loss of co-ordinate expression of progesterone receptors A and B is an early event in breast carcinogenesis. Breast Cancer Res. Treat. 72, 163-172, https://doi.org/10.1023/A:1014820500738

171 Hopp, T.A., Weiss, H.L., Hilsenbeck, S.G., Cui, Y., Allred, D.C., Horwitz, K.B. et al. (2004) Breast cancer patients with progesterone receptor PR-A-rich tumors have poorer disease-free survival rates. Clin. Cancer Res. 10, 2751-2760, https://doi.org/10.1158/1078-0432.CCR-03-0141

172 McFall, T., McKnight, B., Rosati, R., Kim, S., Huang, Y., Viola-Villegas, N. et al. (2018) Progesterone receptor A promotes invasiveness and metastasis of luminal breast cancer by suppressing regulation of critical microRNAs by estrogen. J. Biol. Chem. 293, 1163-1177, https://doi.org/10.1074/jbc.M117.812438

173 Mote, P.A., Gompel, A., Howe, C., Hilton, H.N., Sestak, I., Cuzick, J. et al. (2015) Progesterone receptor A predominance is a discriminator of benefit from endocrine therapy in the ATAC trial. Breast Cancer Res. Treat. 151, 309-318, https://doi.org/10.1007/s10549-015-3397-0

174 Rosati, R., Oppat, K., Huang, Y., Kim, S. and Ratnam, M. (2020) Clinical association of progesterone receptor isoform A with breast cancer metastasis consistent with its unique mechanistic role in preclinical models. BMC Cancer 20, 512, https://doi.org/10.1186/s12885-020-07002-0

175 Ross, M.B., Buzdar, A.U. and Blumenschein, G.R. (1982) Treatment of advanced breast cancer with megestrol acetate after therapy with tamoxifen. Cancer 49, 413-417, https://doi.org/10.1002/1097-0142(19820201)49:3\%3c413::AID-CNCR2820490303\%3e3.0.C0;2-S

176 Alexieva-Figusch, J., van Gilse, H.A., Hop, W.C., Phoa, C.H., Blonk-van der Wijst, J. and Treurniet, R.E. (1980) Progestin therapy in advanced breast cancer: megestrol acetate-an evaluation of 160 treated cases. Cancer 46, 2369-2372, https://doi.org/10.1002/1097-0142(19801201)46:11\%3c2369::AID-CNCR2820461111\%3e3.0.C0;2-3

177 Pannuti, F., Martoni, A., Di Marco, A.R., Piana, E., Saccani, F., Becchi, G. et al. (1979) Prospective, randomized clinical trial of two different high dosages of medroxyprogesterone acetate (MAP) in the treatment of metastatic breast cancer. Eur. J. Cancer 15, 593-601, https://doi.org/10.1016/0014-2964(79)90097-5

178 Pannuti, F., Martoni, A., Cilenti, G., Camaggi, C.M. and Fruet, F. (1988) Adjuvant therapy for operable breast cancer with medroxyprogesterone acetate alone in postmenopausal patients or in combination with CMF in premenopausal patients. Eur. J. Cancer Clin. Oncol. 24, 423-429, https://doi.org/10.1016/S0277-5379(98)90012-8

179 Klijn, J.G., de Jong, F.H., Bakker, G.H., Lamberts, S.W., Rodenburg, C.J. and Alexieva-Figusch, J. (1989) Antiprogestins, a new form of endocrine therapy for human breast cancer. Cancer Res. 49, 2851-2856 
180 Perrault, D., Eisenhauer, E.A., Pritchard, K.I., Panasci, L., Norris, B., Vandenberg, T. et al. (1996) Phase II study of the progesterone antagonist mifepristone in patients with untreated metastatic breast carcinoma: a National Cancer Institute of Canada Clinical Trials Group study. J. Clin. Oncol. 14, 2709-2712, https://doi.org/10.1200/JC0.1996.14.10.2709

181 Romieu, G., Maudelonde, T., Ulmann, A., Pujol, H., Grenier, J., Cavalie, G. et al. (1987) The antiprogestin RU486 in advanced breast cancer: preliminary clinical trial. Bull. Cancer 74, 455-461

182 Robertson, J.F., Willsher, P.C., Winterbottom, L., Blamey, R.W. and Thorpe, S. (1999) Onapristone, a progesterone receptor antagonist, as first-line therapy in primary breast cancer. Eur. J. Cancer 35, 214-218, https://doi.org/10.1016/S0959-8049(98)00388-8

183 Jonat, W., Bachelot, T., Ruhstaller, T., Kuss, I., Reimann, U. and Robertson, J.F. (2013) Randomized phase II study of lonaprisan as second-line therapy for progesterone receptor-positive breast cancer. Ann. Oncol. 24, 2543-2548, https://doi.org/10.1093/annonc/mdt216

184 Lanari, C., Wargon, V., Rojas, P. and Molinolo, A.A. (2012) Antiprogestins in breast cancer treatment: are we ready? Endocr. Relat. Cancer 19, R35-R50, https://doi.org/10.1530/ERC-11-0378

185 Engman, M., Skoog, L., Soderqvist, G. and Gemzell-Danielsson, K. (2008) The effect of mifepristone on breast cell proliferation in premenopausal women evaluated through fine needle aspiration cytology. Hum. Reprod. 23, 2072-2079, https://doi.org/10.1093/humrep/den228

186 Klijn, J.G., Setyono-Han, B. and Foekens, J.A. (2000) Progesterone antagonists and progesterone receptor modulators in the treatment of breast cancer. Steroids 65, 825-830, https://doi.org/10.1016/S0039-128X(00)00195-1

187 Women's Health, I. (2002) Risks and benefits of estrogen plus progestin in healthy postmenopausal women: principal results From the Women's Health Initiative randomized controlled trial. JAMA 288, 321-333, https://doi.org/10.1001/jama.288.3.321

188 Beral, V. (2003) Breast cancer and hormone-replacement therapy in the Million Women Study. Lancet 362, 419-427, https://doi.org/10.1016/S0140-6736(03)14596-5

189 Horwitz, K.B., Sartorius, C.A., Hovland, A.R., Jackson, T.A., Groshong, S.D., Tung, L. et al. (1995) Surprises with antiprogestins: novel mechanisms of progesterone receptor action. Ciba Found. Symp. 191, 235-249

190 Patel, B., Elguero, S., Thakore, S., Dahoud, W., Bedaiwy, M. and Mesiano, S. (2015) Role of nuclear progesterone receptor isoforms in uterine pathophysiology. Hum. Reprod. Update 21, 155-173, https://doi.org/10.1093/humupd/dmu056

191 Figueroa, V., Rodriguez, M.S., Lanari, C. and Lamb, C.A. (2019) Nuclear action of FGF members in endocrine-related tissues and cancer: Interplay with steroid receptor pathways. Steroids 152, 108492, https://doi.org/10.1016/j.steroids.2019.108492

192 Doci, C.L., Mikelis, C.M., Callejas-Valera, J.L., Hansen, K.K., Molinolo, A.A., Inoue, A. et al. (2017) Epidermal loss of Galphaq confers a migratory and differentiation defect in keratinocytes. PLoS ONE 12, e0173692, https://doi.org/10.1371/journal.pone.0173692

193 Cottu, P.H., Bonneterre, J., Varga, A., Campone, M., Leary, A., Floquet, A. et al. (2018) Phase I study of onapristone, a type I antiprogestin, in female patients with previously treated recurrent or metastatic progesterone receptor-expressing cancers. PLOS ONE 13, e0204973, https://doi.org/10.1371/journal.pone.0204973

194 Lee, O., Sullivan, M.E., Xu, Y., Rodgers, C., Muzzio, M., Helenowski, I. et al. (2020) Selective progesterone receptor modulators in early stage breast cancer: a randomized, placebo-controlled Phase II window of opportunity trial using telapristone acetate. Clin. Cancer Res. 26, 25-34, https://doi.org/10.1158/1078-0432.CCR-19-0443

195 Lee, O., Pilewskie, M., Karlan, S., Tull, M.B., Benante, K., Xu, Y. et al. (2021) Local transdermal delivery of telapristone acetate through breast skin, compared with oral treatment: a randomized double-blind, placebo-controlled Phase II trial. Clin. Pharmacol. Ther. 109, 728-738, https://doi.org/10.1002/cpt.2041 